\title{
THE EFFECT OF POST TYPE AND LENGTH ON THE FRACTURE RESISTANCE OF ENDODONTICALLY TREATED TEETH
}

\author{
By
}

\author{
John Duncan McLaren, D.D.S.
}

\begin{abstract}
A thesis submitted in partial fulfillment of the requirements for the degree of Master of Science in Restorative Dentistry
\end{abstract}

\author{
The University of Michigan \\ School of Dentistry \\ Ann Arbor, MI \\ 2003
}

Thesis Committee:

Dr. Peter Yaman, D.D.S., M.S.; Chairman

Dr. Joseph Dennison, D.D.S., M.S.

Dr. Neville McDonald, D.D.S., M.S.

Dr. Warren Wagner, M.S., Ph.D. 


\section{DEDICATION}

This thesis is dedicated to my mentors throughout my educational experience and to my

family whose unwavering support has always allowed me to strive toward the highest of goals. 


\section{ACKNOWLEDGEMENTS}

Many thanks to the following people:

Dr. Peter Yaman for his support as my thesis advisor and his wonderful mentorship. The lessons learned from you go well beyond dentistry.

Dr. Joseph Dennison for his insight and research savvy. Your guidance has been most appreciated.

Dr. Neville McDonald for his helpfulness. It has been a pleasure to have you serve on my thesis committee.

Dr. Warren Wagner for his friendship and exquisite technical approach to solving problems. Your generosity to serve on my committee is highly valued. I look forward to many years of collaboration with you to improve dentistry.

Ken Guire for his expert statistical assistance and analysis.

Dr. Patricia Bauer for her help with endodontic procedures.

Dr. Alberto Herrero for his assistance in mechanical testing of teeth. Your expertise and patience is greatly appreciated.

Dr. John Powers and Dr. Huan Lu for their timely assistance in flexural modulus testing of posts.

General Dentistry Clinic staff for their assistance and willingness to try new things throughout my residency. You all managed to effectively handle my many different techniques and materials. Bea Burgett, you are an awesome assistant and wonderful person.

Dr. Marcela Newman for her direction and guidance in helping me to select this project. Your friendship and enthusiasm made my time in Grad Op special.

My parents, John and Ning, for a lifetime of support and unconditional love.

My loving grandmother and aunt whose generosity will not be forgotten.

Dr. Gabriella Mantellini, Dr. Hana Al-Dohan, Dr. Scott Kooistra, and Dr. Charles McLaren. You all have been a remarkable group of friends and classmates and I look forward to twenty years from now seeing the great achievements you all have made.

And finally a special heartfelt thanks to Scott and Charles for the years of solidarity, both inside and outside the clinic. You guys made the last three years memorable and worthwhile. 


\section{TABLE OF CONTENTS}

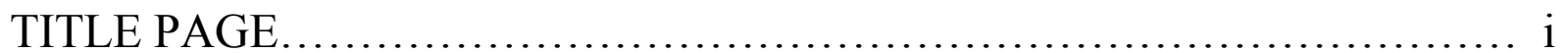

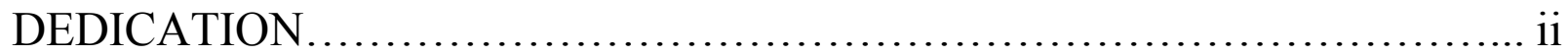

ACKNOWLEDGEMENTS ............................................... iii

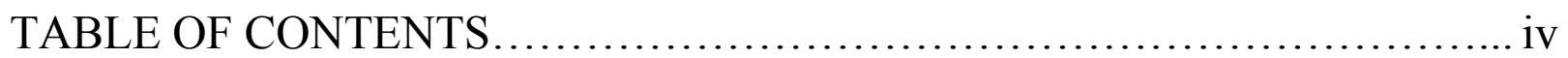

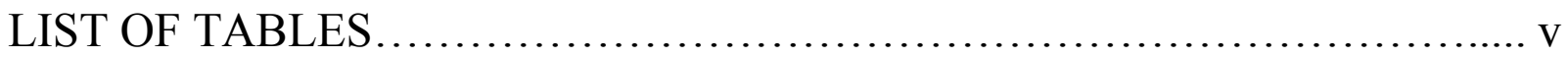

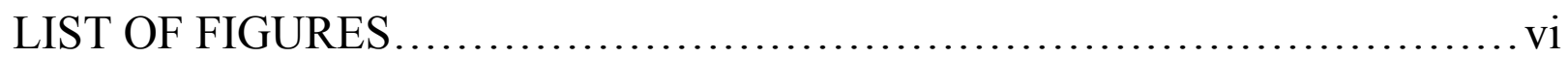

\section{CHAPTER 1}

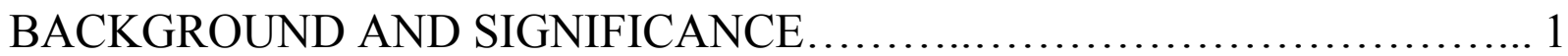

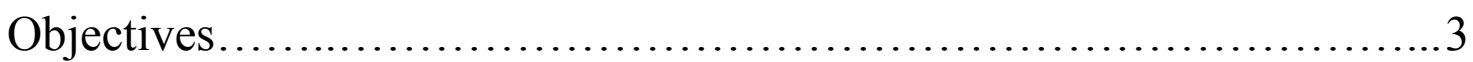

Hypotheses....................................................... 3

REVIEW OF THE LITERATURE ............................................ 4

Clinical performance............................................... 4

Microleakage....................................................... 6

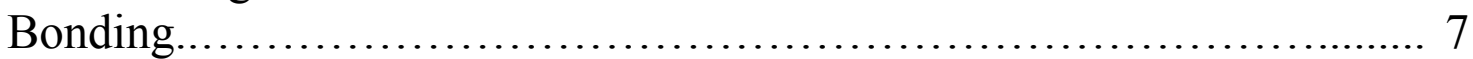

Retention.......................................................... 9

Post effect on remaining tooth....................................... 18

Root reinforcement............................................... 19

Post removal.......................................................... 22

Mechanical testing................................................... 22

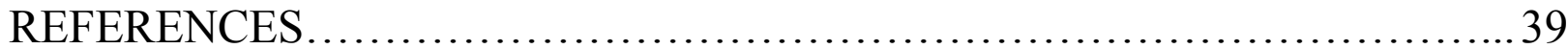

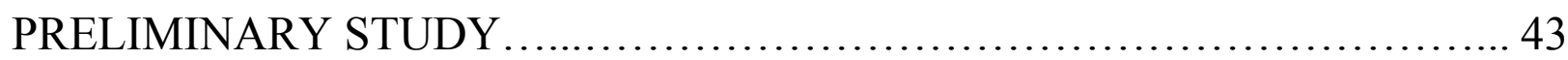

\section{CHAPTER 2}

THE EFFECT OF POST TYPE AND LENGTH ON THE

FRACTURE RESISTANCE OF ENDODONTICALLY TREATED TEETH

ABSTRACT ................................................................. 47

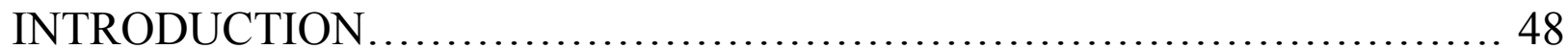

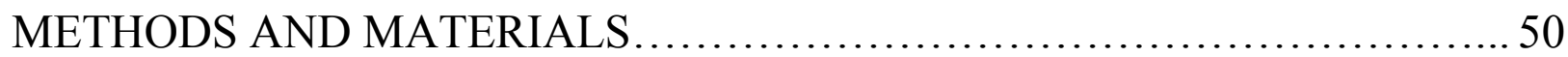

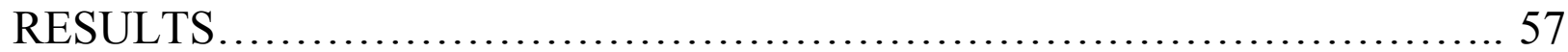

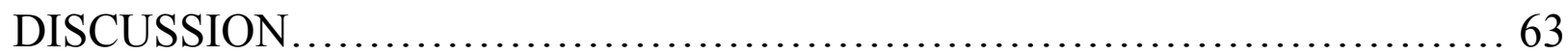

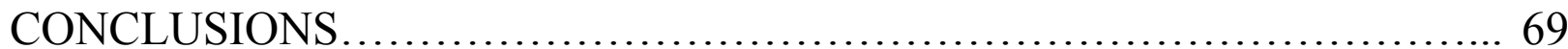

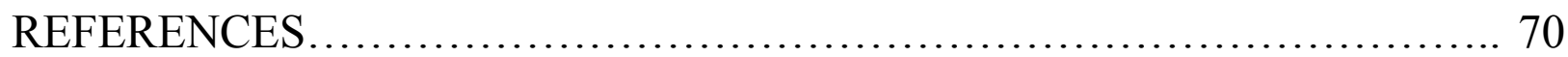

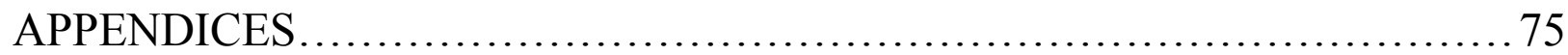




\section{LIST OF TABLES}

\section{CHAPTER 1}

Table 1. Mechanical data for Tested Posts (Reproduced from

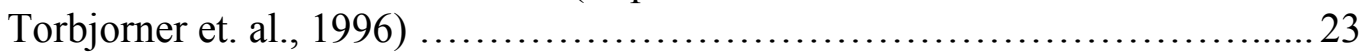

Table 2. Experimental Setup of Posts Tested at Respective Lengths ..................... 43

Table 3. Pilot Study Load Values Using FibreKor Posts …..........................44

\section{CHAPTER 2}

Table 1. $\quad$ Experimental Design for Testing ........................................ 51

Table 2. Average Diameter and Flexural Modulus for Different Post Types...............57

Table 3. Group Differences of Least Squares Means Using 1-way ANOVA for Initial Failure Load After a Bonferroni Adjustment.......................... 59

Table 4. 2-way ANOVA for Initial Failure Load Based on Post Type and Post Length.

Table 5. Post Type and Length differences of Least Squares Means Using 2-way ANOVA for Initial Failure Load After a Bonferroni Adjustment. ...

Table 6. Group Differences of Least Squares Means Using 1-way ANOVA for Ultimate Failure Load After a Bonferroni Adjustment.

Table 7. 2-way ANOVA for Ultimate Failure Load Based on Post Type and Post Length.

Table 8. Post Type and Length differences of Least Squares Means Using 2-way ANOVA for Ultimate Failure Load After a Bonferroni Adjustment......61

Table 9. Mode of Ultimate Failure for Test Groups. 


\section{LIST OF FIGURES}

\section{CHAPTER 1}

Figure 1. Effect of post length on core bond failure load (Pilot study).....................45

Figure 2. Effect of post length on maximum failure load (Pilot study).................... 45

\section{CHAPTER 2}

Figure 1. Parapost XP, Light Post and Snowlight posts ...........................50

Figure 2. Silicone simulated periodontal ligament space (in black)...................53

Figure 3. $\quad$ Prefabricated Delrin $®$ sleeve and alignment post.......................... 53

Figure 4. Translucent VPS core former using post and prefabricated

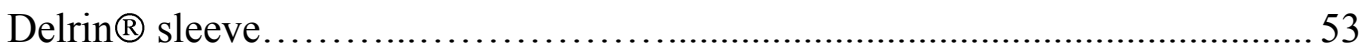

Figure 5. Core and post space after prefabricated Delrin ${ }^{\circledR}$ sleeve removed.................53

Figure 6. Post cemented and core material injected into space to create core............ 53

Figure 7. Core former removed and core finished to $4 \mathrm{~mm}$ height....................53

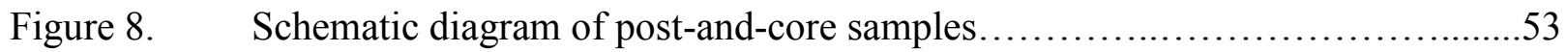

Figure 9. Sample mounted $1 \mathrm{~mm}$ from CEJ $\quad$...................................5

Figure 10. Typical loading curve for sample showing initial failure and

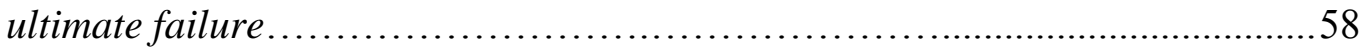

Figure 11. Average initial failure load based on post type and post length..................58

Figure 12. Average ultimate failure load based on post type and post length..............60

Figure 13. Parapost XP $10 \mathrm{~mm}$ showing vertical core fracture $\quad$......................62

Figure 14. Average ultimate failure load based on post type and post length..............62

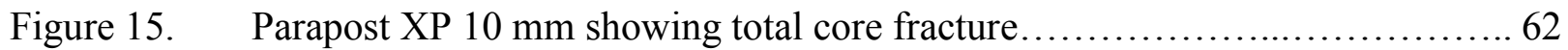


Figure 16. Light Post $10 \mathrm{~mm}$ showing tooth-core debond, core fracture, and

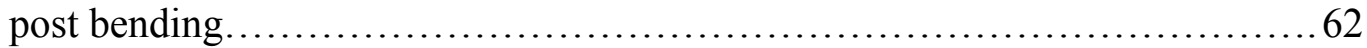

Figure 17. Parapost XP $5 \mathrm{~mm}$ showing tooth-core debond and subsequent root fracture... 62

Figure 18. Snowlight $5 \mathrm{~mm}$ showing tooth-core debond, post bending, and post pullout ...62

Figure 19. Snowlight $5 \mathrm{~mm}$ showing post pullout and core-post debonding..............66 


\section{CHAPTER 1}

\section{INTRODUCTION}

\section{Background and Significance}

The use of metallic posts in the restoration of endodontically treated teeth has been a mainstay in dentistry. However, metallic posts present with several clinically significant deficiencies. A dark shine through effect may be evident when using metallic posts and cores. In addition, metallic posts may cause discoloration of the surrounding tissues due to corrosion products. This is an esthetic concern, especially in the restoration of anterior teeth. Furthermore, metallic posts have a greater stiffness than the surrounding dentin, leading to increased stress concentration within root structure and possible root fracture during masticatory function. The advent of non-metallic posts has begun to address these concerns. Carbon and glass fiber-reinforced posts have been developed with stiffness values closer to that of human dentin. Esthetic posts made from glass or quartz fiber allow improved esthetics when allceramic crowns are to be placed. With the wide range of non-metallic posts being introduced and used in clinical dentistry, it is important to understand the properties of these materials and their limitations.

In vitro mechanical testing of post-and-core treated teeth provides information as to failure characteristics given a particular loading scenario. Factors that play a role in fracture resistance of a post-and-core system include, but are not limited to, the amount of tooth remaining, the post design, post length, post stiffness, and the type of core material. In addition, several studies have examined the impact of a crown ferrule placement around a tooth for improving retention and fracture resistance. However, few studies have examined the clinical situation where a sufficient ferrule cannot be placed. In clinical cases where little or no coronal tooth structure remains and crown lengthening is not an option, use of a post-and-core restoration serves as the primary source of retention for a crown.

Ideally a balance between the post length within root and the coronal extension should exist. With previous pre-fabricated post systems, authors have indicated varying theories on this balance. Some have advocated the use of the longest post possible as long as the apical seal is not disturbed. Others have advocated that the post be longer than the crown or that the post should be a certain fraction of the length of the root. Most of these studies have emphasized the 
post length requirements in order to achieve sufficient retention and rigidity for coronal restoration. However, with the use of resin cement, post retention is improved over conventional zinc phosphate or glass-ionomer cement. Studies have shown that the post length can be decreased by up to two-fold without significant loss of retention when resin cement is used. The advent of fiber-reinforced pre-fabricated posts has allowed for direct adhesive bonding to the post. Therefore, it is theorized that with improved retention of these bonded posts, the post length within root should be minimized but still able to maintain sufficient coronal rigidity. In addition, by minimizing the post length, the root canal seal may be better maintained and post retrieval made easier in the event of failure.

However, the fracture resistance of these newer fiber-reinforced posts has been brought into question, particularly when used in clinical situations where little or no coronal tooth structure remains. Manufacturers of fiber posts and other researchers have focused their attention on the similar elastic moduli of certain fiber posts (21 GPa) and human dentin (18 GPa). According to manufacturer's claims, this similarity of stiffness allows for a more even stress distribution to the root. However, the fiber-reinforced materials are anisotropic, having different mechanical properties depending on the direction of loading. While the elastic moduli gives the stiffness of the post in the longitudinal direction, the flexural modulus is representative of the stiffness of a material when a bending force (transverse) is applied. The flexural modulus is the ratio of stress to strain during flexural loading of a material. It is most often quoted when citing flexural properties and is the tangent of a stress/strain curve where the plastic has not yet deformed. The flexural modulus of a fiber post may be a more clinically relevant measure since deformation of the post typically occurs in the transverse direction. Only a few studies have even made indirect reference to the flexural modulus of a fiber post and the significance it has on fracture resistance. The purpose of this thesis research is to investigate the effect of post type and length on the fracture resistance of endodontically treated teeth restored with composite cores using three different pre-fabricated post systems. 


\section{$\underline{\text { Objectives }}$}

\section{Primary objectives}

1) Determine the mean failure loads for each treatment group (7).

2) Determine the mode-of-failure for each treatment group (7).

\section{Secondary objectives}

1) Determine the relationship between the post length with the mean failure loads and summarize the clinical implications.

2) Determine the relationship between the flexural moduli of each post system with the mean failure loads and mode of failure and summarize the clinical implications.

\section{Hypotheses}

1) $\mathrm{H}_{\mathrm{o}}$ : There is no statistically significant difference in the mean failure loads between the post systems tested at each of the respective lengths.

$\mathrm{H}_{\mathrm{a}}$ : There is a statistically significant difference in the mean failure loads between the post systems tested at each of the respective lengths.

2) $\mathrm{H}_{\mathrm{o}}$ : There is no statistically significant difference in the mean failure loads between the different post lengths tested for each respective post system.

$\mathrm{H}_{\mathrm{a}}$ : There is a statistically significant difference in the mean failure loads between the different post lengths tested for each respective post system. 


\section{REVIEW OF LITERATURE}

\section{Clinical performance}

The clinical performance of fiber posts has been evaluated by several authors up to six years post-placement. While two studies have focused solely on carbon fiber posts, one has also looked at glass fiber post success. Although there is no standardization of coronal restorations over the post-and-cores evaluated, the studies provide valuable information as to how the posts can be expected to perform in routine clinical applications.

Fredriksson et. al. (1998) performed a retrospective study of 236 patients with teeth restored by carbon fiber-reinforced epoxy resin posts (Composipost) in Sweden. ${ }^{1}$ Patients treated with carbon fiber posts were selected randomly from seven dentists from five regions in Sweden. Of the patients selected, 146 agreed to a clinical examination to evaluate the post tooth and a contralateral tooth. The remaining 90 patients were evaluated via their treatment records only. The final restorations of the carbon fiber post treated teeth were PFM restorations ( $80 \%)$, all-ceramic crowns (10\%) and composite (10\%). Also looked at and recorded at the pre-op and post-op evaluation were the opposing occluding teeth, periodontal conditions, and surrounding bone height. Follow-up radiographs were examined for signs of technical failures, root fracture, or post fracture. The clinical examinations were carried out by two calibrated observers. The authors found no Composipost failures due to fracture over the duration of service of 2-3 years. No dislodgment, fracture of roots, or caries were observed in the carbon fiber treated teeth. They estimated a 98\% success rate of the Composipost system. All periodontal indices indicated that the treated teeth were statistically similar to the control teeth. However, mesial bone height was found to be significantly different $(\mathrm{p}<0.05)$ compared to control teeth. They concluded that of the $2 \%$ of teeth with failure, the failure was not attributable to the Composipost system. In addition, they found no differences in the periodontal condition of teeth other than the mesial bone height.

This study is important since it presents one of the first in-vivo retrospective reviews of the carbon fiber post. The extremely high success rate is encouraging, but the amount of remaining tooth structure following the post placement was not mentioned. The design of the crown and whether a ferrule was created in the tooth were not disclosed. The ferrule design has been shown to increase the fracture resistance of teeth. ${ }^{2}$ The mesial bone height difference 
between the control group and the carbon-fiber group is intriguing. It should be noted that the distal bone height was also found to be different between groups at a 10\% significance level. The authors provide an additional study that confirms the mesial bone height discrepancy, but offer no explanation or discussion about the finding. It is possible that increased flexure of the posts places greater cervical stresses on the root and may lead to premature bone height loss.

Ferrari et. al. (2000) presented data on the clinical performance of carbon fiber and glass fiber posts ranging from 1-6 years after placement. ${ }^{3}$ A total of 1304 posts were placed by three dentists. The C-Post had an average service of 46 months, the Aestheti-Posts averaged 14 months, and the Aestheti-Plus averaged 13 months in service since recall. The clinical distribution of the posts was fairly equal, with posts placed in all areas of the mouth including both anterior and posterior teeth. Final restorations placed on the treated teeth consisted of metal ceramic restorations $(52 \%)$, ceramic crowns $(38 \%)$ and resin-based composite $(10 \%)$. The clinical procedure for placement of the posts was consistent, with at least $4 \mathrm{~mm}$ of gutta-percha left apically. The posts were bonded with a bonding resin cement and cores were fabricated in composite. Success of the posts was assessed by clinical and intraoral radiographic examinations by two dentists independently. The results showed a success rate of $96.8 \%$, with 25 failures due to post debonding and 16 failures due to endodontic reasons. No technical failures due to the fiber posts were recorded. Debonding occurred during removal of temporary restorations in teeth with less than $2 \mathrm{~mm}$ residual coronal dentin remaining. These teeth either had the post replaced or the same post rebonded. There were no statistical differences in failure rate found among the post groups.

This study shows that the strength of the post may not be as significant in clinical success as the post retention and preventing leakage within the canal. Indeed, the goals of restoring endodontically treated teeth seem to be to preserve as much remaining dentin as possible, place a conservative post with adequate retention, and keep the apical seal of the root canal. A longer post length creates increased retention, but may compromise the apical seal of the canal. A shorter post length may preserve the apical seal but may lead to a loss of post retention.

Ferrari et. al. (2000) also presented a 4 year clinical evaluation of fiber posts compared to cast post and cores. ${ }^{4}$ A total of 200 endodontically treated teeth were divided into groups of 100 
samples each. In the carbon fiber group, teeth were prepared with adhesively bonded Composiposts with lengths of $9 \mathrm{~mm}$. Teeth were built up using a self-curing composite core material. In the cast post-and-core group, impressions were made of the post space and posts cast in a precious alloy. Cast posts were cemented using zinc phosphate cement. All teeth received a PFM crown as the final restoration. Periapical radiographs were taken immediately after, 6 months, 1, 2, and 4 years after crown cementation to evaluate the teeth. The carbon fiber group was found to have a $95 \%$ clinical success rate, with $2 \%$ endodontic failure. No dislodgement or fracture of posts or roots was found. The cast post-and-core group had an overall success rate of $84 \%$, with $3 \%$ endodontic failure, $9 \%$ root fracture, and $2 \%$ dislodgment of the crown. The results were statistically significant, showing better clinical success with the carbon fiber group than cast post-and-cores over a 4 year period.

Despite the random division of teeth into the two groups, it was unclear as to the preparation design of the crown and whether a ferrule was used. Also, the distribution of teeth (anterior versus posterior) was not given, and is important in interpreting the results from a comparative study such as this. However, the three retrospective studies give a good estimate of the high success rate found with carbon and glass fiber posts in controlled clinical situations.

\section{$\underline{\text { Microleakage }}$}

Long term success of a post-and-core treated tooth depends on the ability of the system to prevent microleakage. Microleakage may cause cement washout, recurrent caries, or failure of the root canal treatment. One study looked at the effect of cyclic loading on the amount of microleakage in endodontically treated teeth restored with fiber posts.

Mannocci et. al. (2001) used 72 mandibular premolars for in vitro testing of microleakage when restored with fiber post systems. ${ }^{5}$ Following root canal preparation and obturation, the canals were filled with either a ZOE temporary material or composite without adhesive. Temporary fillings were removed after 1-week storage in saline and post spaces were prepared to $9 \mathrm{~mm}$ length. Two types of carbon-quartz fiber posts were adhesively cemented in the spaces using either All Bond 2, Panavia 21, Panavia F, or non-adhesively cemented using zinc phosphate. Composite cores were fabricated around the posts to a height of $4 \mathrm{~mm}$. Fatigue testing was performed using 300,000 cycles and a $125 \mathrm{~N}$ load at a $45^{\circ}$ angle. After testing, the 
core interfaces of the teeth were immersed in a Rhodamine B solution for 2 days and dye penetration was measured. It was found that the resin cement groups leaked significantly less than the group cemented with zinc phosphate. Between the resin cement groups, the All Bond 2 dentin bonding group leaked less than the teeth restored with Panavia cement. Leakage was found to occur in all specimens, with the average ratio of dye infiltration/root canal interface being between $0.70-0.87$ for the resin cement specimens. It was concluded that a multiple step dentin bonding agent (All Bond 2) allowed for a better marginal seal than that obtained with self-etching bonding agent (Panavia 21 and Panavia F).

This study simply shows that under cyclic loading conditions, even adhesively cemented fiber posts exhibit microleakage. A more predictable bonding system may allow for a decrease in microleakage within a post-and-core system. The integrity of a post-and-core is vital to retaining a coronal seal to prevent microleakage.

\section{Bonding}

Effective bonding to root dentin is essential in order to maximize the potential of resin cement when cementing a post. Clinically, when the cement bond fails, the retention of the post is reduced. Although the post may not entirely dislodge, the risk of root fracture is increased due to the uneven stress distribution created. In addition, with the loss of post retention and stability, the core and crown may become loose, leading to microleakage and ultimate failure. Several studies have looked at the quality of an adhesively bonded post within a root given different bonding techniques,

In a case study presented in 2000, Ferrari and Mannocci evaluated the resin-canal wall interface after using a one-bottle adhesive system to bond a fiber post. ${ }^{6}$ A patient with a maxillary central incisor with previous endodontic treatment and need for extraction consented to the bonding procedure. The root canal was prepared for a post space to a depth of $9 \mathrm{~mm}$ and the canal was etched, dried, and bonded using two consecutive coats of a bonding agent. A 1.4 $\mathrm{mm}$ diameter carbon fiber post was then cemented using a self-cure resin cement and a crown build-up was performed with resin composite. One week thereafter, the root was extracted and split-fractured mesiodistally. Using SEM, it was found that a hybrid layer formed with a thickness between $3-5 \mu \mathrm{m}$ and resin tag length of $10-20 \mu \mathrm{m}$. In the coronal third of the prepared 
root space, the resin tag density was higher than that observed in the middle and apical thirds. It was theorized that the best bond surface was present in the coronal $3 \mathrm{~mm}$ of the specimens. This study shows that effective apical root bonding may be difficult to achieve. Therefore, even with proper technique, additional length of a post may not be well bonded toward the apex.

Mannocci et. al. (1999) used confocal and scanning electron microscopy (SEM) to evaluate the interface between the post, cement, and dentin with fiber posts and titanium posts. ${ }^{7}$ Using forty-two single-rooted lower premolars, seven groups were tested, including several carbon fiber posts. Two different dentin bonding systems were also used. Posts were adhesively cemented and Rhodamine B was mixed with the dentin primer to allow for identification of the resin-dentin interdiffusion zone. Teeth with cemented posts were sectioned parallel to the long axis and the halves were observed using either confocal microscopy or SEM. It was found that the most consistent resin-dentin interdiffusion zone was with a $4^{\text {th }}$ generation dentin bonding agent. In the most apical part of the canals only dental adhesive was found without composite cement. In addition, SEM analysis showed that the fiber posts all had some voids in their structure.

This study lacked a control group and suffered from an ineffective comparison between groups. Although the differences in dentin bonding were elucidated, the relevance to a clinical situation was limited. Adhesive bonding of posts may be better understood when a combination of microscopic analysis and mechanical testing is performed.

In an attempt to find a better method for bonding fiber posts into root canals, Vichi et. al. (2002) tested two clinical procedures. ${ }^{8}$ The authors used twenty teeth extracted due to periodontal problems. The teeth were sectioned at the CEJ and were endodontically treated. In one experimental group, Scotchbond MP was applied with a microbrush tip. In another group Scotchbond MP was applied using a small plastic brush provided by the manufacturer of the adhesive. Both groups had translucent fiber posts cemented using resin cement. Following split-fracturing along the long axis of the tooth, it was found using SEM analysis that samples using the microbrush showed a uniform resin-dentin interdiffusion zone. In addition, the resin tags formed in the coronal, middle, and apical areas showed a similar morphology. Samples that had bonding agent applied using a plastic brush showed a less uniform interdiffusion zone and 
had a lower density and shorter resin tag formation in the apical third. It was theorized that use of a microbrush for intraradicular bonding agent placement provided a predictable resin-tag and hybrid-layer formation throughout the root structure.

\section{$\underline{\text { Retention }}$}

Retention of posts is paramount for the integrity of a post-and-core tooth. It is believed that the longer the post within the canal, the more retentive it becomes. However, with the advent of adhesive cementation and increased cement strengths, it may be possible to shorten the post length without significant change in retention. In addition, the design of many fiber posts enables a clinician to bond to the post surface as well as root dentin.

Stockton (1999) presented a literature review about the factors that affect post retention. ${ }^{9}$ Included in these factors were post design, length, diameter, luting agents, luting method, canal shape, preparation of the canal space and tooth, and the location in the dental arch. The author suggests that the longer the post, the greater the retention and the less the deflection imposed on the root. Post diameter should be controlled to preserve root structure. Posts should not exceed one third of the root diameter wherever possible and should have a tip of $1 \mathrm{~mm}$ diameter or less to minimize apical stress concentration. For post design, the best combination of retention and low stress concentration is a well-adapted parallel-sided post. A threaded post provides the best retention, but at a cost of high stress levels created within the root. The effect of luting agents on post retention and strength have been thoroughly investigated. Some studies have shown that the use of resin cements may increase post retention. This may allow for shorter posts to be used and also a more uniform stress distribution to root structure. Conversely, the use of a shorter post may affect the strength of the retained core. This interaction between a resin cement, post length, and core strength has not yet been determined. However, the angle of loading has a big impact on the success of a post-and-core system. The maxillary anterior region is considered a high risk area for failure due to the shear forces created from the lingually directed loading during function. As concluded, the retention and resistance to fracture are both key when fabricating a post-and-core retained restoration. The goal is to maximize retention without compromising the integrity of the root with excess removal. 
Duncan and Pameijer (1998) conducted an in vitro study to compare the retention of titanium posts using six different luting systems. ${ }^{10}$ Specifically, they intended to compare resin and resin-ionomer cements in terms of retention of posts. One-hundred twenty maxillary and mandibular anterior teeth were sectioned approximately $1 \mathrm{~mm}$ coronal to the CEJ. The canal systems were instrumented, cleaned, and obturated with gutta percha and AH26 sealer. Each root was mounted in a copper cylinder and a Parapost drill was used to create a $9 \mathrm{~mm}$ post space with a $1.25 \mathrm{~mm}$ diameter. Posts were then cemented according to the manufacturer's instructions with either zinc phosphate, glass ionomer, hybrid ionomer, or a resin cement, with each group having 20 specimens. Specimens were then tested in retention using a clamp with an S-hook at the apical end of the mounted specimens to allow for long axis tensile loading. It was found that the highest retention values were with a hybrid ionomer cement and two resin cements. Zinc phosphate provided the least retention. The authors noted that the resin-cement systems were observed to have a cement failure prior to the load at which the post could be removed from the canal. This may indicate that although the cement bond was disrupted, the cement may have remained bonded to portions of the post or root, preventing complete dislodgement. In a clinical situation, this may lead to leakage within the canal, weakening of the core, and an increased likelihood of root fracture.

Overall, this study enforces the retentive potential of resin cement systems for cementing posts but questions the integrity of the cement bond.

In 1998, Cohen et. al. conducted a study to test the retention of endodontic posts cemented with either a resin composite, a glass ionomer, a hybrid glass ionomer, or zinc phosphate. ${ }^{11}$ A total of 160 human single-rooted teeth were used with the crowns removed at the CEJ. The three posts tested were a $1.65 \mathrm{~mm}$ diameter titanium Flexi-Post, a $1.35 \mathrm{~mm}$ diameter AccessPost, and a $1.25 \mathrm{~mm}$ diameter Parapost. The posts were cemented according to manufacturer's instructions to lengths of $11 \mathrm{~mm}$. Samples were tested for tensile strength using a specialized jig to grasp the coronal portion of the post. Failure occurred when the post was removed from the tooth. It was found that the resin cement had the highest overall average retention of all the cements studied. In addition, the passive posts (AccessPost and Parapost) had less retention than the threaded split-shank post. 
This study helps to reinforce the idea that resin cement can improve retention of posts, especially those with passive fits which rely on the cement for retention. Although the threaded post had the greatest retentive values, the increased stress distributed to the root and the increased likelihood for root fracture during loading was not discussed. It was found that the glass ionomer cement had the lowest average retentive values, likely due to its low compressive strength. A higher strength adhesive cement such as a resin cement may allow for an increased retention strength of posts.

Love and Purton (1998) presented a similar study on the retention of posts. ${ }^{12}$ Using 1.5 $\mathrm{mm}$ stainless steel posts in single-rooted anterior and premolar teeth, five different cements were tested for the effect on the retention of the posts. The cements used were a glass-ionomer cement, two hybrid ionomer cements, and two resin cements. The resin cements used include a system with a dentin bonding agent (Scotchbond MP) and a universal resin cement (Panavia 21). Teeth were sectioned horizontally $1 \mathrm{~mm}$ above the facial CEJ and canals were endodontically treated. Post spaces of $10 \mathrm{~mm}$ depth were placed and the posts were cemented with one of the cements according to manufacturer instructions. The coronal extension of the post was grasped using a vise and tested for tensile force. The results of the testing indicated that the adhesively bonded resin cement provided the most retention for the posts, followed by the glass ionomer. The two hybrid ionomer cements had low retention values. Posts cemented with the Scotchbond MP resin cement showed an adhesive failure at the cement-post interface while the Panavia 21 specimens showed adhesive failure at the cement-dentin interface. This may be attributed to incomplete bonding to the root dentin with Panavia 21 compared to Scotchbond MP which has a separate etch process to facilitate bonding.

This study serves to emphasize the importance of adhesive bonding when using resin cements to cement posts. While the authors neglect a discussion on the mechanical properties of cements and the effect on retention, it is clear that the combination of adhesive bonding and high strength provided by resin cements result in significant improvement in retention for prefabricated posts.

Drummond (2000) evaluated the pull out strength and flexural strength after thermal cycling of stainless steel posts and three different fiber posts. ${ }^{13}$ The posts tested included a 
carbon fiber post, stainless steel post, an Aesthetic post (carbon/quartz post), a Light post (glass fiber post), and FibreKor post (glass fiber post). Extracted third molar human teeth were prepared for the respective posts, with a sample size of 20 posts per group. One group of teeth were thermocycled. Teeth were embedded in denture acrylic and the posts were adhesively cemented using the manufacturer designated bonding system. The depth of the post space was $7-8 \mathrm{~mm}$ and the diameters ranged from $1.30 \mathrm{~mm}$ to $1.76 \mathrm{~mm}$, depending on the post. Posts were secured in a specially designed collet to grip the post during shear loading at $2 \mathrm{~mm} / \mathrm{min}$. and the shear load was measured. To test the flexural strength, a three point loading test was used. The average shear load was not significantly different between the post groups but did vary from $26.2 \pm 7.8 \mathrm{~kg}$ for the stainless steel post to $11.5 \pm 5.6 \mathrm{~kg}$ for the glass fiber post. No difference was found between multi-step versus single-step bonding agents in terms of pullout strength. The flexural strength of the posts showed that thermal cycling weakened the posts as the highest strength carbon fiber post $(1492 \pm 19 \mathrm{MPa})$ was significantly stronger than the thermal cycled FibreKor post $(666 \pm 26 \mathrm{MPa})$.

The presented study did not standardize samples well. This was evident with the presentation of the shear bond strength of posts where the post length varied from $6.6 \pm 1.4 \mathrm{~mm}$ to $8.1 \pm 1.1 \mathrm{~mm}$. In addition, different bonding systems and different diameter posts were used. The experimental setup of gripping the posts may have induced pre-stresses into the fiber posts along the length of the post fibers. This may account for the generally lower shear loads found with the fiber posts compared to the stainless steel post. It is clear that thermal cycling serves to decrease fiber post strength. However, it is equally unclear as to the effect of adhesive cementation on fiber post retention.

Stockton and Williams (1999) compared the retention and shear bond strength of $1.4 \mathrm{~mm}$ and $1.8 \mathrm{~mm}$ diameter carbon-fiber posts (C-Posts) and a $1.5 \mathrm{~mm}$ diameter Parapost Plus. ${ }^{14}$ The premise behind their study was that the success of post and core restorations is highly dependent on the stiffness and strength of the post used. They indicate that previous studies that tested the strength of a post and core created both a shear and compressive component. The shear component was likely the cause of failure. Therefore, a stiffer and stronger post would provide more resistance to a shear stress, leading to a reduced risk of failure. Using seventy-two maxillary incisors and canines, the authors removed the crowns to a level $1 \mathrm{~mm}$ coronal to the 
CEJ. They performed endodontic treatment and then vertically mounted the teeth in acrylic resin. Post spaces were prepared to $7 \mathrm{~mm}$ in length using the respective post drills. Paraposts were cemented with a glass ionomer and the C-Posts were adhesively cemented with a resin cement. One group of teeth were only tested for retention of the posts. Another group of teeth had composite cores adhesively built-up around the post and were tested for strength by loading at a $45^{\circ}$ to the long axis of the post. It was found that the $1.8 \mathrm{~mm}$ diameter C-Posts had significantly higher retention than the $1.4 \mathrm{~mm}$ diameter C-Posts and the Paraposts. The C-Posts had primarily adhesive failure between the cement and the tooth. The load to failure for the three groups were not found to be statistically different. All the post and core specimens experienced a peak load and then experienced a slow catastrophic failure. The Parapost samples tended to have failure at the core/root interface while the C-post samples tended to have diagonal fracture of the root. The smaller $1.4 \mathrm{~mm}$ diameter C-post had several post fractures.

It is possible that the posts or cores may have initially debonded, causing an increased stress concentration within the cervical portion of the root due to the core flexure. Although this was not elaborated by the authors, this may be the reason for the diagnosis of the high incidence of root fractures. The authors instead suggest that the low stiffness of the post may have transferred the stresses into the surrounding composite core, resulting in the subsequent root fracture. An evaluation of the remaining post bonding may have confirmed whether this theory was feasible. The theory that the flexural or elastic modulus of the post impacts the strength of the core warrants investigation, as does the theory that debonding at the post/root interface or the core/root interface may lead to early failure.

Recently in 2002, Gallo et. al. performed an in vitro comparison of the retention of composite fiber and stainless steel posts. ${ }^{15}$ Single canal premolars were sectioned $1 \mathrm{~mm}$ coronal to the CEJ but no endodontic treatment was performed on the teeth. A post space was prepared to $9 \mathrm{~mm}$ in length and $1.25 \mathrm{~mm}$ in diameter. The stainless steel posts were cemented using zinc phosphate. For the glass fiber posts, the spaces were prepared to $9 \mathrm{~mm}$ in length and either 1.00 $\mathrm{mm}, 1.25 \mathrm{~mm}$ or $1.50 \mathrm{~mm}$ diameter. Canals were etched and bonded using the bonding system supplied with the post kit. Silane agent was applied to the posts and they were cemented using a resin cement. The coronal extension of the post was grasped with a chuck attached to the testing machine and all specimens were loaded in tension until failure. The results showed that the 
stainless steel posts had a significantly greater retention strength than the fiber posts. The 1.25 $\mathrm{mm}$ and $1.50 \mathrm{~mm}$ fiber post groups had similar retention strengths and were more retentive than the $1.00 \mathrm{~mm}$ diameter fiber post group. The resin cemented fiber posts had only adhesive failures at the tooth-cement interface while the zinc phosphate cemented stainless steel posts had mixed failures. The authors concluded that the greater retention for the $1.25 \mathrm{~mm}$ and $1.50 \mathrm{~mm}$ fiber post groups compared to the $1.00 \mathrm{~mm}$ group may have been due to the greater surface area for bonding or an increased post rigidity. They also concluded that the resin cemented posts may have had a lower retention strength than the zinc phosphate cemented stainless steel posts due to inadequate penetration of bonding system components.

Despite the interesting results, there are two primary concepts to take from the study. First, in order to achieve adequate bonding within root, it is paramount that canals be prepared properly to achieve truly adhesive bonding of a post. Theoretically, adhesive bonding to the root should provide improved retention compared to conventional zinc phosphate cement. Second, the structural design of fiber posts differs from conventional stainless steel or titanium posts. The longitudinal fibers may incur stresses along the post when clamped for retention testing. In addition, the serrated design of some fiber posts may allow for greater transmittal of these stresses within the post. It is important to translate these findings into a loading situation similar to an intraoral condition. This includes testing the effect of adhesive resin cementation of stainless steel and fiber posts on the support for a core.

In a 1994 study, El-Mowafy and Milenkovic compared the retention of stainless steel Paraposts cemented with six different cement systems and with two different post lengths. ${ }^{16}$ Using forty-two mandibular premolars and canines, the crowns were sectioned $1 \mathrm{~mm}$ above the $\mathrm{CEJ}$ and the root canals were instrumented to $8 \mathrm{~mm}$. Posts were then cemented using either zinc phosphate or one of five different resin cement systems. Following storage in water at $37^{\circ} \mathrm{C}$ for 24 hours, the posts were uniaxially tested in tension until post separation from the root interface occurred. It was found that Paraposts cemented with the resin cements all had mean separation forces greater than those cemented with zinc phosphate. The Prisma Universal Bond 3/Biomer and Scotchbond Multi-Purpose/Resiment cements both had significantly greater separation forces than the other cement systems used. In addition, adhesive failure at the dentin-cement interface of the post occurred in all of the resin cement specimens, while the zinc phosphate 
specimens had mainly cohesive failure within the cement. The authors also tested the effect of post length on the retention of the Paraposts using maxillary and mandibular molars. Three cement systems were then used to cement the posts: Fleck's zinc phosphate cement, Prisma Universal Bond 3/Biomer cement, and All-Bond2/All-Bond C\&B Luting Cement. It was found that reducing the Parapost length from $8 \mathrm{~mm}$ to $5 \mathrm{~mm}$ did not have a significant effect on the post retention force for each of the three cements tested.

This study provided a worthy investigation as to the influence of resin cement on post retention. In fact, the authors believe that the bonding of the resin cement can help to offset a reduced post length without significant loss of retention. The authors mention the difficulty in predictably placing cement to the apical extent of the root canal. Given the small sample size for each group, this may account for the large standard deviations in the groups. However, the conclusions are broad and point to the theoretical and measured usefulness of resin cement to aid in retention of posts.

In 2001, Nissan et. al. performed a study to measure the retention with reduced post lengths. ${ }^{17}$ Both a parallel-sided stainless steel post (Parapost) and a threaded tapered post (Dentatus SST) were tested at lengths of 5, 8, and $10 \mathrm{~mm}$. One-hundred twenty single-rooted teeth were used with the coronal portion sectioned at the CEJ. Root canal instrumentation and obturation was performed. Teeth were tested for retention using either a composite resin cement or zinc phosphate cement at one of the three post lengths. Using a one-way ANOVA, it was found that there were no significant differences in retention for either 5,8 , or $10 \mathrm{~mm}$ lengths when the composite resin cement was used to cement the posts. However, the non-adhesive zinc phosphate cement showed significant differences, with the $10 \mathrm{~mm}$ length being the most retentive and the $5 \mathrm{~mm}$ least retentive. The parallel-sided posts showed greater retention for all groups than the threaded tapered posts. The resin cement was found to have failed cohesively, with cement remaining on the canal walls and also on the posts. The authors concluded that use of a resin cement may allow for shortened posts. The shortened posts can improve tooth survival by preserving root structure without compromising the apical seal.

This study clearly shows the potential of adhesive resin cementation on improving the retention of posts. It is thorough and well-organized and the statistical analysis allows for a solid conclusion regarding retention of shortened posts. While an admirable premise, it is important 
to distinguish between static and dynamic loading. Including this study, all retention studies to date have focused on static tensile loading. A post may not fail under static loading, but the repetitive stresses created with dynamic loading may translate into failure. Although a post may remain retained within the root, if the core fractures or debonds due to post bending, the restoration may be considered a failure. Likewise, a short post may be retained but at the expense of increased coronal stresses within the root. Therefore, it is important to delineate the effect of shortening a post in terms of the risk of root fracture, core fracture, and core debonding.

Cohen et. al. (1992) compared the retention of apically shortened pre-fabricated posts. ${ }^{18}$ Using 100 single-rooted teeth, post spaces were prepared at full length for two different diameter threaded, split-shank Flexi-Posts. Other groups had the post spaces apically reduced successively by $1 \mathrm{~mm}$. Thus, post spaces ranged from full length to approximately half the full length specified by the post design. Posts were luted to the roots using zinc phosphate cement. Posts were mounted for mechanical testing and the load to retention failure was measured. It was found that the full length posts were most retentive on average, but were not statistically different than the other lengths. Posts shortened by $5 \mathrm{~mm}$ to about half the length had significantly less retention than the full length post.

The results of the study indicate that in certain instances a post may be shortened without significant loss of retention. Although this study used zinc phosphate as the luting agent, use of an adhesive resin cement with improved strength may also allow for better retention of shortened posts. The impact of post shortening on the stress distribution of the post within the root, the mode of failure, and core integrity was not discussed but warrants further investigation.

Hagge et. al. (2002) compared the effect of different thicknesses of resin cement on the retention of posts within roots. ${ }^{19}$ Using single-rooted teeth with the crowns removed at the CEJ, the roots were cleaned, shaped, and filled with gutta percha. Post spaces were drilled to four different diameters: $1.27 \mathrm{~mm}, 1.35 \mathrm{~mm}, 1.45 \mathrm{~mm}$, and $1.49 \mathrm{~mm}$. The post spaces were then etched and primed and resin cement was dispensed into the canal space using a 20-gauge needle tube. Stainless steel Paraposts of $1.24 \mathrm{~mm}$ diameter were then coated with cement and placed as close to the center of the dowel space as possible. Thus, the average cement space in the four groups was $15 \mu \mathrm{m}, 55 \mu \mathrm{m}, 105 \mu \mathrm{m}$, and $125 \mu \mathrm{m}$, respectively. It was found that the $1.45 \mathrm{~mm}$ 
diameter post space (105 $\mu \mathrm{m}$ cement space) produced the highest retention values, followed by the $1.49 \mathrm{~mm}$ diameter post space (125 $\mu \mathrm{m}$ cement space). It was concluded that the Paraposts cemented with resin cement showed significantly greater retention in slightly oversized canal spaces. The resin cement may have needed adequate space in order to provide retention strength to the posts. It was found that the smallest cement space $(15 \mu \mathrm{m})$ failed exclusively by cohesive cement failure while the larger cement spaces failed primarily at the cement-tooth interface.

This study had several flaws to the experimental design that detract from the conclusions. There was no standardization of the cement thickness circumferentially around the post. Posts were placed in the approximate center of the canal space, leaving room for error in the cement thickness. The broadest statement that can be made is that under controlled conditions, a slightly oversized canal space may improve retention of posts when using resin cement.

In 1996, Love and Purton presented a study on the serrations of carbon fiber posts and their effect on the post retention, core retention, and rigidity of the post. ${ }^{20}$ Three groups of posts were used: Composipost (with serrations), Composipost (without serrations), and Parapost. The rigidity test was performed using a three-point bending test. The deflection of the posts was measured against the applied force to create a force/deflection graph. In addition to the core material, the authors tested the retention of the post to human root canals. Twenty single-rooted teeth were endodontically treated, sectioned $1 \mathrm{~mm}$ coronal to the labial CEJ and post-holes prepared to a depth of $10 \mathrm{~mm}$. The post-holes were prepared according to manufacturer's recommendations and posts were cemented using resin cement. Teeth were embedded in acrylic resin blocks and tested in tension using the same methodology as a previous study. ${ }^{21}$ The results allowed the authors to conclude that the rigidity of the serrated carbon-fiber post was similar to the Parapost but significantly less than a non-serrated carbon-fiber post. The retention of the serrated Composipost to the core was acceptable, and the retention to the root was statistically similar to that of the Parapost system.

This study was one of the first to test the effect of serrations on the properties of the Composipost system. However, the mechanical testing and retention testing lacked a conventional methodology. As was mistaken in other studies, the measurement of stress is not in kilograms but rather as a load applied over a given area. Therefore the data presented can only be used within the context of the study itself. 


\section{Post effect on remaining tooth}

The influence of post length on the retention of a restoration has been researched by several authors. In addition, the post length influences the stability of the remaining root and the stress distribution within the root.

Leary et. al. (1987) evaluated the effect of post length on the rigidity of root. ${ }^{22}$ Maxillary central incisors and canines were endodontically treated to a size 50 file. Obturation of the canal was not performed. The posts used were 0.05 " pre-fabricated stainless steel. Specimens were mounted in a copper ring with type IV dental stone and a pretest control and seven post tests were made. Measurements were made at progressive degrees of preparation and post placement beginning with endodontic treatment only progressing to post preparations with post placement to $9 \mathrm{~mm}$ in length. The mounting apparatus allowed the load to be applied $10 \mathrm{~mm}$ from the CEJ at 90 degrees to the long axis. Deflection was measured using a strain gage extensometer. It was found that as internal tooth structure is removed that teeth become less stiff. Teeth with cemented posts show more stiffness than non-posted teeth. Cemented posts at $3 / 4$ the root length offer the greatest rigidity when posts are used compared to non-posted teeth. Load transfer to the post within the root occurs with cemented posts and appears to increase with increasing post length.

This study supports the theory that removal of root structure when creating a post space tends to decrease the rigidity of the root. However, it offers evidence that some measure of rigidity is regained when a post is cemented into the post space. The ten samples tested provide qualitative evidence of the stress transfer that occurs with cemented posts and the weakening of roots with progressive post space preparation.

In a 1999 in vitro study, Isidor et. al. assessed the effect of post length and crown ferrule length on the fracture resistance under cyclic loading of teeth restored with posts and cores. ${ }^{23}$ Ninety bovine teeth were divided into nine groups of 10 and mounted in acrylic blocks. Titanium pre-fabricated post lengths of $5 \mathrm{~mm}, 7.5 \mathrm{~mm}$, and $10 \mathrm{~mm}$ and crown ferrule lengths of $0 \mathrm{~mm}, 1.25 \mathrm{~mm}$, and $2.5 \mathrm{~mm}$ were tested in combinations. Posts were cemented with zinc phosphate cement so that $2.5 \mathrm{~mm}$ was left occlusal to the tooth. Composite cores were fabricated and adhesively bonded to the tooth. The total height of the core and ferrule combined 
was $5 \mathrm{~mm}$ for all groups. Crowns were cast with a height of $9 \mathrm{~mm}$ and were cemented with zinc phosphate cement. The specimens were cyclic loaded at $1 \mathrm{~Hz}$ with a $400 \mathrm{~N}$ impact at a $45^{\circ}$ until failure occurred anywhere in the restoration or root. The results found that the group with the largest ferrule $(2.5 \mathrm{~mm})$ and post length $(10 \mathrm{~mm})$ received significantly more loads before failure than the other groups. All specimens from the $5 \mathrm{~mm}$ and $7.5 \mathrm{~mm}$ post groups without a ferrule $(0 \mathrm{~mm})$ failed on the first cycle due to core debonding. All other specimens failed from root fracture. Interestingly, the medium-length post $(7.5 \mathrm{~mm})$ groups showed the least resistance to cyclic loading. It was concluded that for crowned teeth with a post-and-core, increasing the ferrule length is more important than lengthening the post to resist cyclic loading.

This study was simply designed and the discussion of ferrule and post length was well researched. The use of a ferrule to provide retention and resistance to fracture depends primarily on the amount of coronal tooth remaining. In instances were a ferrule cannot be placed, the postand-core are required to provide the retention for a crown. Although this study indicates that no ferrule provides little resistance to fracture, the load used was $400 \mathrm{~N}$, well in excess of reported average intraoral loads of 150-200 N. It would be worthwhile to further investigate methods for improving the strength and retention of a post-and-core where a ferrule cannot be placed.

\section{$\underline{\text { Root reinforcement }}$}

The use of resin cement for post cementation may allow for reinforcement of remaining root structure. In fact, the stress distribution of applied loads may be transferred more evenly down the length of a post when a resin cement is used due to the adhesive properties of the material.

Saupe et. al. performed a study in 1996 to test the intraradicular reinforcement of compromised roots in endodontically treated teeth. ${ }^{2}$ Forty maxillary central incisors were used with the crowns sectioned 1-2 mm above the CEJ. Root canals were instrumented and obturated with gutta percha and AH26 cement. A dowel space of $8 \mathrm{~mm}$ length was created leaving a residual dentinal wall thickness of only 0.5-0.75 $\mathrm{mm}$ at the CEJ. An apical seat of $2 \mathrm{~mm}$ was created using a No. 4 post reamer. This was designed to simulate a compromised root with little remaining axial root dentin. Groups were created as follows: Group A: morphologic (custom) dowel and core; Group B: resin-reinforced root and dowel and core; Group C: morphologic 
dowel and core with $2 \mathrm{~mm}$ ferrule; Group D: resin-reinforced root and dowel and core with 2 $\mathrm{mm}$ ferrule. Dowels were resin cemented and then stored in $37^{\circ} \mathrm{C}$ distilled water and thermocycled 1500 times. Roots were then covered with a self-curing rubber to simulate a periodontal ligament and embedded in acrylic blocks to expose $3 \mathrm{~mm}$ of natural root. Specimens were loaded at $60^{\circ}$ to the long axis and the failure load was recorded. The results showed a significant increase in failure load between the resin-reinforced root and dowel and core specimens (Group B and Group D) compared to the morphologic dowels groups (Group A and Group C). No differences were found between groups with or without ferrules placed. The study indicates that when the remaining root structure is compromised, a clinical alternative is to use intraradicular rehabilitation with resin-reinforcement, which may offer up to $50 \%$ more resistance to fracture than a conventional cast post and core.

This study was important to demonstrate the potential for resin bonding to reinforce remaining root structure. Although there is debate as to whether composite resin placed into a conservative post space for reinforcement offers any additional strengthening of the root, the use of composite resin within compromised roots appears to be viable. This study also tends to indicate that placement of a ferrule may not offer additional strength if the remaining root is thin-walled. However, the site of loading between ferruled and non-ferruled specimens in the study was unclear and therefore may invalidate this finding. It is acknowledged from previous studies that ferrules placed on teeth tend to strengthen the fracture resistance and retention of cores and crowns where little coronal tooth structure remains.

Mendoza et. al. (1997) performed a study similar to Saupe et. al. (1996) to test the ability of a resin-bonded prefabricated post to reinforce a compromised root. ${ }^{24}$ Forty mandibular canine teeth had their crowns sectioned perpendicular to the long axis of the tooth. Roots were cleaned and the canal enlarged circumferentially at the cervical region to leave approximately a $1 \mathrm{~mm}$ thickness of axial dentin and an $8 \mathrm{~mm}$ post space was loosely placed. Four groups of 10 specimens each with metal pre-fabricated posts cemented were tested; Group 1: zinc-phosphate cement; Group 2: Panavia resin cement; Group 3: C\&B Meta-bond resin cement; Group 4: Z100 composite and dual-cure bonding agent. In Group 4, the dual-cure bonding agent was placed and light cured. The composite resin was then placed to fill the root canal system and a plastic post was inserted into the center of the canal. The composite was light cured through the 
plastic post, the post removed, and a metal pre-fabricated post was then cemented with the dualcure bonding agent. All specimens were stored in distilled water at $37^{\circ} \mathrm{C}$ and thermocycled. Mechanical testing was performed at $60^{\circ}$ to the long axis and failure was recorded. The results showed that the posts cemented with Panavia resin cement had the greatest force to fracture. The composite resin cement (Group 4) and C\&B Meta-bond cement (Group 3) showed greater force to fracture than the zinc-phosphate group but were not statistically different. Almost all specimens exhibited vertical fracture of the root, as might be expected in compromised roots.

The study reinforces the results of Saupe et. al. (1996) whereby resin-reinforcement of roots can be accomplished with the use of resin cement. However, unlike that study, the authors found no statistical benefit with composite resin in the post space to reinforce the root. It is likely that the use of a single cement exhibiting high mechanical properties provides the best reinforcement for compromised roots. By minimizing the differences in strength and modulus between the root and cement, a more cohesive post and root interface can be created.

Jiménez (2001) conducted research to test the fracture resistance of teeth restored with fiber-reinforced post systems. ${ }^{25}$ Using ninety maxillary central incisors, samples were made with either narrow or flared canals and a control with a stainless steel Parapost XH was also used. Specimens were endodontically treated and one of three fiber-reinforced posts was placed: a FibreKor post, Dentatus Luscent Anchor, or Ribbond Standard experimental post design. Posts were adhesively cemented using a self-cured adhesive and resin cement. Samples were loaded to failure at a $45^{\circ}$ angle. It was found that there was no statistically significant difference between flared and narrow canals in the mean load to failure except for the Ribbond posts. The fiber post groups were protective to remaining tooth and did not cause root fracture. The metal post control group showed the highest load value but created root fractures during loading.

The suggestion of this study is that resin cement may allow for root reinforcement and a more homogenous post-and-core complex. The transfer of loading stresses within the post to the root may be more uniform with use of a resin cement, and in the case of a flared canal may compensate for the loss of root tooth structure. 


\section{Post Removal}

One of the reported advantages of fiber posts is their ability to be removed easily from the root in cases of endodontic retreatment or post failure. However, unlike traditional metal posts that can often be ultrasonically vibrated loose in a canal, the fiber posts are adhesively bonded and therefore must be drilled out.

De Rijk (2000) reported a technique for removal of fiber posts from endodontically treated teeth. ${ }^{26}$ Prior to fiber posts, the author indicates that removal of posts from endodontically treated teeth has been a major obstacle. A technique is given using a special fiber post removal kit to quickly remove the bonded fiber posts. In removing the posts, a pilot hole is drilled to provide an orientation for a removal drill. Once the removal drill has been used, the post can be further hollowed by a Peeso reamer. It is noted that the entire procedure should not take more than 5 minutes to complete. However, in clinical practice, the technique does not provide for easy removal. Esthetic glass-fiber posts are particularly difficult to remove since they are bonded to and blend in with dentin. A properly bonded fiber post cannot be easily vibrated out of the canal. Fiber posts placed with greater lengths extending into root structure may be even harder to remove. In addition, the longitudinal orientation of the fibers tend to deflect burs in the same axis. It seems clear that a shorter length fiber post with a small diameter would provide the best success for complete post removal.

\section{Mechanical testing}

This section of the review focuses on the mechanical properties of pre-fabricated postand-core restorations. Use of carbon fiber posts predominate in many studies since they have been available longer than glass fiber posts. However, the information presented may in theory be applicable to both types of fiber posts due to their similar design. In addition to comparison studies of metal pre-fabricated and fiber posts, two studies that utilize finite element analysis are presented. These studies provide information on the stress distribution within the root depending on the angle of post loading.

The study by Torbjorner et. al (1996) investigated the mechanical properties of carbon fiber reinforced posts. ${ }^{27}$ The study attempted to determine the effects of water storage and 
thermocycling on the carbon fiber material. Six groups were tested as listed in Table 1, each group having 6 specimens. Posts were subjected to a 3-point loading test and the flexural modulus and strength were determined. The treated carbon fiber groups were also compared using SEM analysis and a cytotoxicity test was performed.

Table 1: Mechanical Data for Tested Posts (Reproduced from Torbjorner et. al., 1996)

\begin{tabular}{|l|c|c|}
\hline \multicolumn{1}{|c|}{ Post type } & Flexural modulus, GPa & Ultimate flexural strength, MPa \\
\hline 1) Composipost - dry & $82 \pm 6$ & $1154 \pm 65$ \\
\hline 2) Composipost - dry, thermocycled & $53 \pm 2$ & $882 \pm 39$ \\
\hline 3) Composipost - wet & $49 \pm 3$ & $803 \pm 27$ \\
\hline 4) Composipost - wet, thermocycled & $41 \pm 2$ & $714 \pm 23$ \\
\hline 5) Parapost Unity No-Ox & $92 \pm 6$ & $1387 \pm 16$ \\
\hline 6) Parapost Unity G-post & $83 \pm 7$ & $1099 \pm 9$ \\
\hline
\end{tabular}

The Composipost carbon fiber post without treatment had comparable flexural modulus and ultimate flexural strength values to the Parapost groups, but the mechanical properties dropped after storage in water or thermocycling. The stress-strain diagrams of all carbon fiber posts showed a large plastic region with catastrophic failure occurring well after the yield strength was reached. SEM investigation showed a reduced adhesion between carbon fibers and matrix after the simulated intraoral conditions. In addition, they concluded that the carbon fiber posts had a flexural strength and moduli necessary to avoid post fracture during intraoral function.

The study was important that since it contributed mechanical information about carbon fiber posts. Further, the effects of water storage and thermocycling of the posts tend to support the idea that the carbon fiber posts are subject to greater degradation than stainless steel posts and this may be of concern intraorally. Taken as a whole, this was a well-designed study that is clinically relevant.

In 2001, Mannocci et. al. performed a three-point bending test of five different types of fiber posts after storage in three conditions for 1 year. ${ }^{28}$ The three conditions were dry storage at room temperature, storage in $37^{\circ} \mathrm{C}$ water, and storage enclosed in bovine teeth immersed in water. The purpose of the study was to test the strength of the posts under different conditions and also observe the failure mode of the posts by confocal microscopy. The results indicate that 
all posts performed similarly with respect to flexural strength except a silica fiber post, which had a reduced strength. Exposure to water weakened the posts significantly while the sealed posts within bovine teeth were similar to the dry posts. From the pretest microscopy, the authors found that many voids were present in each of the posts tested. The carbon fiber posts showed more voids and less fiber adherence to the resin matrix than the other posts tested.

A critique of the study finds that the authors fail to mention the testing jig used in the mechanical testing. In addition, the value of testing the bovine teeth with the sealed posts is not clear. However, it may be inferred that the fiber and matrix composition have an effect on the strength of the post. Exposure to moisture, such as with coronal leakage of a restoration, may reduce the flexural strength of a fiber post and lead to weakening of the adhesive bond to dentin. This is important, as it has been shown that failure of the post cement was the most frequently observed reason for clinical failure. ${ }^{1}$

Purton and Payne (1996) performed an in vitro study comparing the physical properties of carbon fiber-reinforced epoxy resin root canal posts with stainless steel posts. ${ }^{29}$ Using a Composipost, a unidirectional $8 \mu \mathrm{m}$ carbon fiber post system, the authors investigated the flexural stiffness (transverse modulus of elasticity) and the retention compared to a traditional Parapost system. Ten $1.40 \mathrm{~mm}$ diameter carbon fiber posts and ten $1.25 \mathrm{~mm}$ diameter stainless steel posts were tested in three-point bending. In addition to the mechanical testing, the authors tested the tensile bond strength of the posts. Cylindrical blocks of resin composite were placed around the ends of either the carbon fiber or stainless steel posts, allowing gripping of the ends for tensile testing. The results showed the transverse modulus of elasticity to be $213 \mathrm{GPa}$ for the Parapost and $319 \mathrm{GPa}$ for the Composipost. Tensile testing showed significant differences in the average retention forces between the Parapost and Composipost. The Parapost had almost twice the retention force compared to the Composipost. The authors concluded that the carbon fiber post was stiffer in transverse loading than the stainless steel post. In addition, they concluded that the resin core material was retained in tension more strongly to the stainless steel post than the carbon fiber post.

The nature of this study was to compare the carbon fiber and stainless steel root canal posts. With respect to measuring the transverse modulus of elasticity, the results appear to be flawed. It is reported in literature that the elastic modulus for carbon fiber-epoxy materials 
ranges from 45-215 GPa, depending on the angle of testing since the material is anisotropic. ${ }^{27}$ In this study, the authors reported a transverse elastic modulus of $319 \mathrm{GPa}$. Clearly, there is a testing or calculation error in the measurement of the elastic modulus. They also did not perform the standard tensile bond strength experiment, instead relying on a crude method for separating composite from ends of the posts. The results can only be utilized in the context of this testing method and are not comparable to other standard tensile bond tests.

Asmussen et. al. (1999) performed a study to determine the stiffness, elastic limit, and strength of several prefabricated posts. ${ }^{30}$ Different types of posts were used in the study including two zirconia-based posts, a titanium post, and a carbon fiber post. The posts were placed into brass blocks with diameters corresponding to those of the posts. All posts were cemented using a resin cement and allowed to extend $4.8 \mathrm{~mm}$ from the block. Specimens were then tested using an Instron Universal Testing Machine and the stiffness, elastic limit, and ultimate deflection strength were recorded. The authors found that the mechanical properties of the zirconia posts were comparable to each other but significantly better than the carbon-fiber posts. The titanium post and carbon fiber posts displayed plastic behavior during mechanical testing, indicating the ability for flexure during an applied load. On the other hand, both zirconia posts suffered fracture at the elastic limit, indicating brittle behavior.

The study is one that provides mechanical data on the different post systems. The methodology is straightforward but the experimental design is flawed. The mechanical testing angle is not disclosed and the vector of force as tested does not allow for a pure bending strength. Despite this shortcoming, the comparison between materials is noteworthy. As suspected, the zirconia posts fracture catastrophically without significant plastic deformation. In addition, the carbon fiber posts show a low stiffness and elastic limit, but also demonstrate a strength with a large plastic region of deformation. In a clinical situation, the low stiffness of the carbon fiber post may place increased stress on a core and on the cervical portion of a root during loading.

In 1996, Purton and Love performed an in vitro study comparing carbon fiber and stainless steel root canal posts in terms of rigidity and retention. ${ }^{21}$ In addition, they performed electron microscopy of the carbon fiber posts. Using a $1 \mathrm{~mm}$ diameter smooth carbon-fiber post 
and a $1 \mathrm{~mm}$ serrated stainless steel post, they performed a three-point bending test and then a retention test. Ten posts of each type were subjected to a three-point bending test and plots of stress versus deflection were made. To test retention, twenty single-rooted premolar and anterior teeth were used. Teeth were endodontically treated and sectioned $1 \mathrm{~mm}$ above the labial CEJ. Post spaces were drilled to $10 \mathrm{~mm}$ and posts were cemented using resin cement according to the manufacturer's instructions. The posts were then mounted and subjected to tensile force along the long axis of the post. The average bending of the carbon fiber post was found to be significantly greater than the stainless steel post. In addition, the average retention force was found to be lower in the carbon fiber group. The authors concluded that the stainless steel posts proved to be significantly more rigid than the carbon fiber posts. They also concluded that the difference in the retention test was due to the serrations on the Paraposts which led to an increased mechanical retention.

Purton and Love fail to produce good mechanical data on the post systems tested. The electron microscopy as presented was of no importance for the paper and would have been better left out. It is difficult to correlate the results of this study to other similar studies of retention or bond strength due to testing flaws. The information presented on carbon fiber and stainless steel posts can only be used for comparison purposes only.

Dietschi et. al (1997) studied the effect of cyclic loading and thermocycling on five different post-and-core systems including metal prefabricated, carbon fiber, glass fiber, and zirconia-based posts. ${ }^{31}$ For the experiment, forty human maxillary incisors and canines were divided into five groups of eight teeth each. Endodontic treatment was completed on the teeth and crowns were resected at the CEJ. Posts were placed using resin cement and cores built up with a self-cure reinforced composite resin. The specimens were then fatigue tested at a $45^{\circ}$ angle with 250,000 cycles at $70 \mathrm{~N}$ and $1.5 \mathrm{~Hz}$. All specimens were immersed in room temperature saline during the mechanical cycling. Following the mechanical cycling, specimens were subjected to thermocycling of 5,000 one minute cycles. Specimens were then evaluated using SEM for the adhesive interface continuity and cement thickness. The Composipost and Experimental groups both showed interfaces that were acceptable and exhibited few root fractures. The Composipost group was deemed to have behaved satisfactorily with respect to the adhesive interface following testing. 
Due to the problems of post retention and post failure due to debonding, the results from this study were of great interest. However, the overall presentation of this study left much to be desired. The authors' description of the methodology was vague and post cementation was not standardized using the same cement. This in fact was a major problem in the study since the measurements of the adhesive interface was the primary objective. These deficiencies render the study to have little clinical relevance.

In a similar study, Isidor et. al. (1996) evaluated the fracture resistance of bovine teeth treated with carbon fiber posts. ${ }^{32}$ Fourteen bovine teeth with similar dimensions were prepared for post and core restorations. The teeth were first mounted in an acrylic resin block and protruded from the block by $5 \mathrm{~mm}$, with $15 \mathrm{~mm}$ retained within the acrylic. The post spaces were prepared to a length of $8.5 \mathrm{~mm}$ and posts cemented using resin cement. Composite cores were then prepared to a height of $3 \mathrm{~mm}$ with a chamfer finish line $2.5 \mathrm{~mm}$ apical to the core. Crowns were waxed directly on the preparations and given a $45^{\circ}$ occlusal surface. Once cast, the crowns were cemented using zinc phosphate cement. Cyclic loading was then performed at $2 \mathrm{~Hz}$ with a peak load of $250 \mathrm{~N}$ directly perpendicular to the $45^{\circ}$ occlusal surface. Results were compared to a previous study which tested titanium and cast posts. The authors found the carbon fiber posts held up remarkably well under the cyclic loading. None of the fourteen teeth failed, but preliminary root fracture was seen in four specimens. In the previously mentioned study, all of the cast post-and-core teeth failed by root fracture, as did $82 \%$ of the titanium posts. The authors found that the carbon fiber treated teeth were significantly more fatigue resistant than the cast or titanium groups as tested.

Without the reference to the author's previous study, there was no control used and specimens were not properly standardized. Another major concern of the study is the change in methodology during testing. The authors decided to discontinue the cyclic loading of the carbon fiber treated teeth after 260,000 cycles instead of the planned 1,000,000 cycles. However, as they note, four of the specimens exhibited some degree of root fracture after 260,000 cycles. The result of this handling error is an incomplete picture of the fatigue strength of the carbon fiber posts. 
Using an in vitro evaluation of carbon fiber posts in extracted anterior human teeth, King and Setchell (1990) demonstrated that carbon fiber posts exhibited properties comparable with those of existing prefabricated posts. ${ }^{33}$ Forty teeth were mounted in acrylic resin and prepared to receive parallel posts $10 \mathrm{~mm}$ long with a diameter of $1.5 \mathrm{~mm}$. The crown of the tooth was removed $2 \mathrm{~mm}$ above the CEJ and a $1 \mathrm{~mm}$ shoulder was prepared circumferentially. The teeth were then randomly assigned in groups of 10 with posts either being cast, stainless steel or carbon fiber and the core either cast or made of composite resin. A compressive load was placed $5 \mathrm{~mm}$ from the incisal edge at a $130^{\circ}$ angle from the long axis of the tooth. The average stress was determined by recording the compressive load and using an estimated cross-sectional area of the tooth. The cast post and core was found to have a higher mean failure stress compared to the stainless steel post and composite core, but was not significantly different than the carbon fiber post and composite core. In terms of the mode of failure, the authors found that the majority of carbon fiber posts had fracture occur coronally. On the other hand, the majority of the cast and stainless steel posts had fracture occur within the root structure. They concluded that postretained crowns using a prefabricated carbon fiber post exhibited properties comparable with, and in some cases better than, those of existing stainless steel posts.

Despite the favorable results for carbon fiber posts taken from this study, there are several shortcomings. The use of different core materials without a direct comparison between posts is of concern. Also, the cements used should have been the same to standardize specimens for mechanical testing. Even with these shortcomings, this study does recognize the mode of failure of the specimens and identifies the major differences between fiber posts and metallic posts.

Martinez-Insua et. al. (1998) compared the fracture resistance of pulpless teeth. ${ }^{34}$ Using either a cast post-and-core or a carbon-fiber post with a composite core, the authors restored 44 recently extracted premolars. Teeth were endodontically treated, the crowns resected, and $1 \mathrm{~mm}$ wide shoulders prepared around the circumference of each tooth. The post spaces were drilled to a depth of $10 \mathrm{~mm}$ and posts were cemented with Panavia 21 resin cement. Following post and core restoration, the teeth were machined to provide space for a Ni-Cr crown. The Ni-Cr crowns were cemented using glass ionomer cement and teeth were then mounted for fracture resistance testing. The testing was performed with the force directed at a $45^{\circ}$ angle to the long axis of the 
tooth, but without a flat loading surface. The results of the testing showed the mean failure load to be $103.7 \pm 53.1 \mathrm{~kg}$ for the carbon-fiber system, and $202.7 \pm 125.5 \mathrm{~kg}$ for the cast post and core system. The carbon fiber treated teeth tended to show less elastic behavior compared to the cast post and core teeth. The majority of failure for the Composipost system involved coronal fracture of the post, core, or combination of the two. On the other hand, fracture of the cast post and core system tended to be primarily due to root fracture.

This study deviated from other similar studies in that full crowns were placed on the treated teeth and the loading was performed as it might be intraorally without a flat load plane. From a clinical standpoint, this makes the research more relevant. Interestingly enough, the modes of failure for the teeth paralleled what has been seen in other studies. Namely, the carbon-fiber post system tended to fracture coronally, preserving the root, whereas the cast or metal post system tended to cause root fracture.

In 1997, Sidoli et. al. performed an in vitro study that compared the Composipost carbon fiber post system with other systems. ${ }^{35}$ Four groups were tested using a total of forty extracted maxillary central incisors and canines. The teeth were endodontically treated and then mounted in acrylic resin with their crowns sectioned $1 \mathrm{~mm}$ coronal to the CEJ. Shoulder preparations 1 $\mathrm{mm}$ in height and depth were drilled and the post spaces prepared to $10 \mathrm{~mm}$. Posts were shortened to a height $5 \mathrm{~mm}$ above the tooth margin. The post holes were cleaned and the posts cemented using resin cement and the composite core fabricated with a $6^{\circ}$ angle of convergence. Cast post and cores were fabricated using the lost wax technique and cementation was performed using zinc phosphate. Cast crowns were then fabricated and cemented with zinc phosphate. Compressive loading was done using a steel $1 \mathrm{~mm}$ diameter ball-ended head applied to a flat surface of the crown, $50^{\circ}$ from the long axis of the tooth. Failure of the specimens was recorded and the specimens examined to determine the mode of failure. The Composipost group was found to be the weakest while the endodontically treated only group was found to be the strongest. Of the post-and-core restored teeth, the cast post-and-core group provided the highest mean failure stress. The Composipost group was found to fail the most favorably - meaning that the fracture would allow for intraoral retreatment of the tooth. On the other hand, the endodontically treated group and the cast post-and-core group predominantly failed in the root structure, which would likely necessitate extraction of the tooth intraorally. 
The testing procedures were well documented and appropriate, producing acceptable mechanical data. It is interesting to note that the finding of the endodontically treated teeth having the highest mean failure stress is consistent with existing literature, implying that the preparation of the post space weakens the remaining root structure. In addition, the data supports previous studies concerning mode of fracture and fracture strength of the carbon fiber, stainless steel, and cast post-and-core systems. The study nicely consolidates their data and presents it in a useful manner.

Rosentritt et al. (2000) performed mechanical testing on maxillary incisors following thermocycling and cyclic loading. ${ }^{36}$ Fifty-six human maxillary central incisors were divided into groups: 1) Cosmopost (zirconia-based ceramic) with Cosmo core; 2) Titanium post with composite core; 3) Gold alloy post and core; 4) IPS-Empress (leucite-reinforced ceramic) post and core; 5) Vectris (fiber-reinforced) post and composite core; 6) Cosmopost with Tetric composite core. Cores were produced to standardized dimensions using a transparent film mould. The gold post and cores were cemented using zinc phosphate cement. All other postand-core systems were luted using a matching bonding system and resin cement. Thermocycling and cyclic loading was used (6000 cycles, $1.2 \times 10^{6}$ loading cycles at $135^{\circ}$ ). Failure of the specimens was recorded and the mode of failure noted. It was found that the average fracture strength of the titanium post with composite core (2) and the Cosmopost with composite core (6) were the highest among those specimens tested. The study showed that posts had good fracture strength when combined with a composite core. With increasing flexibility of the post, the fracture strength of the post-and-core system decreased. The flexible Vectris post experienced a loosening of the bond to the core. In general, the fracture tests demonstrated an insufficient bond between the post with the root or the composite cores.

Although the study addressed a major topic in post-and-core mechanical properties, it failed on several levels, most notably the lack of post-and-core dimension standardization. Further, while other authors have found root fracture as the primary failure mechanism for postand-core restorations, ${ }^{33,37}$ this study only found failure in adhesion or the coronal portion of the post-and-core restoration. This likely indicates a problem in testing methodology. Due to these shortcomings and the lack of a well-designed statistical analysis, the study fails to provide meaningful clinical information. 
In a 1999 study, Sirimai et. al compared the resistance of extracted teeth treated with post and core systems to vertical root fracture. ${ }^{37}$ Sixty extracted maxillary incisors were selected and were sectioned at the CEJ and endodontically treated. Custom molds were made to preserve the coronal dimensions for fabrication of custom molds for the cores. Teeth were randomly assigned to one of six test groups of 10 specimens: 1) Cast post and core; 2) titanium post with composite core; 3) Ribbond resin post with composite core; 4) Ribbond resin around a titanium post with composite core; 5) Ribbond resin around a stainless steel post with composite core; 6) stainless steel post with composite core. Canals were enlarged up to $1.6 \mathrm{~mm}$ in diameter and prepared $5 \mathrm{~mm}$ coronal to the root apices. Following post placement, cores were fabricated and then specimens were loaded on the palatal surface at a $130^{\circ}$ angle from the long axis of the tooth. The ultimate fracture strength was recorded along with the mode of failure. Results indicated that there were statistically significant differences among the groups for mean load of failure. The cast post and core demonstrated the highest average failure load while the Ribbond resin post and composite core produced the lowest average failure load. The reinforcement Ribbond fibers were found to increase the failure load for the stainless steel system, but decrease the failure load for the titanium post system. The mode of failure was also found to vary depending on the system, with the fiber-reinforcement systems typically failing by fracture of the composite core. Stiffer metal posts typically failed by vertical root fracture.

This study is important in several ways. First, the design of the study was well-thought out. The authors clearly identify differences among the tested groups and their significance in possible clinical situations, especially in terms of vertical root fracture. By showing the mode of failure, the authors provide valuable information which is clinically relevant. The effect of the polyethylene woven fiber ribbon in reducing vertical root fractures was clearly shown in this study. The flexible fiber-reinforced post shifts the load to a composite core, increasing the risk of core fracture.

Pegoretti et. al. (2002) simulated the mechanical response to applied loads of fiber reinforced posts using a bidimensional model. ${ }^{38} \mathrm{~A}$ finite element mesh was created for four models including an unrestored tooth, a gold alloy post and core, a carbon fiber post, and a glass fiber post. Prototypes of the glass fiber post were created in order to measure the elastic properties in the transverse plane. The models were established with a cross-section stress 
measurement occurring at a location across the root beneath the level of bone. Three different types of loads were simulated: $100 \mathrm{~N}$ vertical load applied to the top of the crown, a $50 \mathrm{~N}$ oblique load at $45^{\circ}$, and a $10 \mathrm{~N}$ horizontal load to simulate external traumatic forces. The Von Mises equivalent stress and shear stress were measured for each of the models in cross-section. It was found that with a vertical load, the fiber posts concentrated stress at the cervical margins of the crowns. The authors believed that this was due to the core material having a lower elastic modulus compared to the surrounding materials. The gold post and core created less stress at the cervical interface. With an oblique load, the glass fiber post had the highest value of internal stress concentrated near the outer dentin surface. The horizontal load simulated a blunt traumatic force. It was believed by the authors that this load is one of the major causes of post crown failure. The gold post and core and carbon fiber post produced the highest internal stresses. On the other hand, the glass fiber post created a concentration of forces at the cervical margin of the crown restoration. Clinically this may lead to fracture failure of the post or marginal gap opening and microleakage when fiber-reinforced posts are used. Overall, it was found that the gold cast post and core created the greatest stress concentration at the post-dentin interface. The glass fiber post does respond similar to a natural tooth except at the cervical margin, which creates a high force concentration due to the difference in the moduli of the post, core, and crown.

Although the study utilizes a computer generated FE analysis of a simulated post and core restoration, it clearly indicates the differences in stress concentrations given different post and core materials. With use of a more flexible post, the stress concentration is transferred toward the cervical of the tooth at the core/tooth interface. With a stiffer post, the stress is transferred more uniformly to the surrounding dentin within the root. The idea of stress transfer from the post is crucial in establishing the viability of a post and core system. Failure of a post and core system can occur several ways. One way is by loss of retention of the post. Assuming a uniform bonded post in the case of a fiber post, the loss of retention may be less important. Another way is by flexure of the post and subsequent failure of the post or another component in the complex such as the core, crown, or root. This study gives empirical evidence that depending on the loading scenario, fiber posts may not be suitable for restoration of a tooth with little or no remaining coronal structure. 
In a 2001 study, Yang et. al. utilized a two-dimensional finite element model to analyze post and core designs. ${ }^{39}$ The objective was to show differences in the load characteristics of a post and core depending on the load direction and design of the post. A standard was used simulating a PFM crown, parallel-sided gold post and core, and a $3.5 \mathrm{~mm}$ gutta-percha apical seal. Four post designs were created and three load angles were simulated. The post designs utilized a gold post with either a parallel or taper shape and varying lengths and diameters. The load angles were vertical, horizontal, and a $20^{\circ}$ diagonal load. The results of the finite element analysis indicated that greater deflection and stresses were generated with the horizontal loading than the other loading directions. No relationship between post design and the pattern of deflection was found. Vertical loading distributed the stress more uniformly between the crown and the post and core. The quantitative differences of stress values of all five prosthesis designs considered were less than $50 \%$, but the angle of loading produced more than a $200 \%$ difference in the calculated stress values. Horizontal loading with differences in post length produced the most dramatic differences compared to a vertical loading situation. For instance, a short post produced the greatest peak dentinal stresses when a horizontal force was applied.

The design of a post and core has an impact on the overall stress distribution and fracture resistance of a restored tooth. However, for in vitro studies, it is impossible to accurately correlate the failure loads to an intraoral environment. Numerous studies have looked at cyclic loading to simulate masticatory movements. However, the intraoral environment creates a dynamic loading situation in which the load angle changes with each contact. Therefore, for in vitro studies, it may be prudent to focus on the most traumatic situation where a horizontal load is applied. As shown in the study, the horizontal loading application creates the greatest difference in stress distribution between post and core designs.

Akkayan et. al. (2002) performed a study to test the fracture resistance of endodontically treated teeth restored with different post systems. ${ }^{40}$ A focus of the study was to compare posts with different elastic moduli and their effect on fracture resistance of teeth. The crowns of forty extracted maxillary canines were sectioned at the CEJ and canals were endodontically treated using gutta-percha and AH 26 sealer. Posts were sectioned to $11 \mathrm{~mm}$ and post spaces prepared to a depth of $8 \mathrm{~mm}$. Three different posts were used: titanium (1.60 mm diameter), quartz fiber (1.70 $\mathrm{mm}$ diameter), glass fiber $(1.50 \mathrm{~mm}$ diameter $)$, and zirconia (1.70 mm diameter). All posts 
were adhesively cemented with resin cement. Following cementation, a light-cured composite core was fabricated and a beveled crown preparation made on the core. Crowns were waxed using a polycarbonate crown form as a matrix, and a Ni-Cr alloy was cast from the wax pattern and luted to the cores with a glass ionomer cement. Specimens were mounted $2 \mathrm{~mm}$ below the CEJ and a silicone layer simulated the PDL. Specimens were loaded at $130^{\circ}$ to the long axis and the fracture load and mode of fracture determined. It was found that the highest fracture resistance was recorded for the quartz fiber group $(91.20 \mathrm{~kg})$ followed by the zirconia group $(78.91 \mathrm{~kg})$, glass fiber group $(75.90 \mathrm{~kg})$, and the titanium group $(66.95 \mathrm{~kg})$. Teeth restored with the quartz and glass fiber posts showed favorable fractures occurring within the core, crown, or cervically at the core interface. Titanium and zirconia posts created primarily catastrophic fractures occurring near the post apex or within the root.

The authors found that the high modulus of elasticity of posts transmitted forces directly to the post/tooth interface without stress absorption. It was concluded that the lower elastic modulus posts allowed for a favorable fracture and a higher static load to failure at a load angle of $130^{\circ}$. The results of the study tend to support the theory that the lower elastic modulus posts allow better stress transmission to the remaining root structure. However, the authors may have had difficulty determining the site and load at which failure occurred within the fiber post specimens due to the covering aspect of the crown over the post and core. It is possible that core debonding or post failure may have occurred prior to the measured failure load. The result of the debonding would have been an increase in cervical stress concentration and a favorable fracture near the core/root interface.

Mollersten et. al. (2002) tested the strength of several core and post-and-core systems. ${ }^{41}$ Using 15 molars and 30 premolars, several different systems were tested in vitro. The teeth were mounted in plastic tubes with acrylic resin and sectioned to a flat coronal surface. Edges of the occlusal surface were beveled at a $45^{\circ}$ angle. Post and cores were fabricated on the teeth. The groups tested on molar teeth were: a) pin-retained cores using a silver-reinforced glass ionomer cement; b) pin-retained cores using composite resin; c) gold pins and cores cemented with zinc phosphate cement. The groups tested on premolar teeth were: a) gold pins and cores cemented with zinc phosphate cement; b) gold post and cores in endodontically treated teeth; c) Composipost carbon fiber post and acrylic resin in endodontically treated teeth. The specimens 
were loaded to failure at $90^{\circ}$ to the long axis of the tooth at a notch $6 \mathrm{~mm}$ from the core margin. The results showed that the composite resin and glass ionomer core specimens fractured in the core surrounding the retentive pins. The carbon fiber post and cores failed from fractures in the resin cement but had a similar strength as the gold post-and-core. According to the authors, a $90^{\circ}$ angle for loading and no crown coverage were chosen to better reflect the ultimate strength of the test specimens and provide a worst-case scenario.

This study provides evidence that at a load angle of $90^{\circ}$, the use of a post may be negligible in providing any additional strength to the core compared to parapulpal pin retention. However, it was unclear as to the mode of fracture of the specimens with regard to the remaining root structure. Although the gold pins and core and gold post-and-core provided the best strength values, they likely also created the most stress on the remaining tooth. In a clinical situation, failure with gold pins and core may involve the remaining root and deem a tooth unrestorable. It is worth investigating the mode of failure of additional scenarios at a similar load angle.

Huysmans et. al. (1992) performed mechanical loading at different angles to test the failure characteristics of post-and-cores. ${ }^{42}$ Ninety-one single- and multi-rooted maxillary premolar teeth were endodontically treated and the coronal portion was removed. All teeth had post spaces prepared to $8 \mathrm{~mm}$ and titanium posts cemented with Panavia Ex. Restored teeth either had an amalgam core, bonded composite core, or glass-cermet core placed using a split mold. Teeth in each restoration group were subjected to one of three loading angles of either 10 , 45 , or $90^{\circ}$ to the long axis of the tooth. The load was applied in the coronal $1.5 \mathrm{~mm}$ of the core using a steel cap until catastrophic failure occurred. It was found that the $10^{\circ}$ loaded specimens had the highest average failure load. The lowest average failure load was found with the $90^{\circ}$ loading angle. The amalgam specimens had the highest load to failure at $10^{\circ}$, while the composite specimens had the highest load to failure at $90^{\circ}$. However, the composite specimens showed a two-phase failure process where the post dislodged and core debonded, followed by core fracture. The authors concluded that the glass-cermet core produced a low failure load, while amalgam and composite were equally suitable for core fabrication.

The results enforce the idea that at a $90^{\circ}$ load angle, the post provides reduced support for a core. Mechanical loading tends to produce a bending force on the post and core whereby the 
core-tooth interface is primarily affected. In clinical practice, this would result in the loss of seal or dislodgement of the post and subsequent bacterial contamination or catastrophic root fracture.

In a similar study using teeth in vitro, Cormier et. al. (2001) compared the fracture resistance and mode of failure of post systems at various stages of restoration. ${ }^{43}$ Mandibular premolars were endodontically treated and $8 \mathrm{~mm}$ post spaces were prepared. Six post systems at four stages of restoration were tested for fracture resistance with a static load. The six post systems included a titanium post, stainless steel post, carbon fiber post, carbon-quartz fiber post, glass fiber post, and a ceramic post. The different stages of restoration were the a) post only; b) the post cemented into a tooth; c) the cemented post with a composite core; and d) crown coverage of the post and core. Posts were cemented using the resin cement recommended by the manufacturers. Composite cores were fabricated to a height of $5 \mathrm{~mm}$ using a standardized matrix shell. Crown fabrication involved preparing the core with a $1 \mathrm{~mm}$ shoulder, a height of 4 $\mathrm{mm}$, and an angle of convergence of $6^{\circ}$. Custom cast gold crowns were then fabricated and cemented using a resin-modified glass ionomer cement. Specimens were loaded to failure at an angle of $90^{\circ}$ to the long axis of the tooth and post. The results found that titanium posts showed a significantly higher failure load through all 4 stages of testing. However, the strength increase through the 4 stages of testing was less than the other post systems. The weakest post in each of the 4 stages of testing was the glass fiber post. The glass fiber posts and cores failed via release of the core and a gradual separation at the tooth/core interface with no damage to root structure. The glass fiber post system benefited the most in strength from full coronal coverage but may still be too weak to effectively support a core and crown in the case of no remaining coronal tooth structure. The metal titanium and stainless steel posts showed a bending failure whereby the root tended to fracture. These posts could not be removed easily. It was concluded that the fiber posts provided an advantage over the metal posts in retrievability and favorable fracture patterns.

Despite the complexity of the study, it shows the influence of coronal coverage on the strength of a post and core complex. The authors used a wide variety of materials to restore the systems and the post diameters and designs were not standardized. The weakest post in the restorations was found to be the glass-fiber post, but it also had the smallest diameter and a serrated design. In order to correct this deficiency, post diameters and materials should be 
similar to allow direct comparison of the fracture resistance values. This study provides a good basis for future in vitro mechanical testing of pre-fabricated posts.

In a 1998 study by CRA Journal, seven post types and two controls were tested for strength contribution to a core buildup. ${ }^{44}$ Maxillary central incisors were prepared for post placement by removing the crown at the facial CEJ and placing the posts to a length of $9 \mathrm{~mm}$, leaving $4 \mathrm{~mm}$ of exposed coronal post. Post types tested included stainless steel, titanium, titanium alloy, carbon fiber, zirconia-dioxide, carbon-quartz, and polyethylene fiber-reinforced. A dual-cure composite and an unrestored tooth were used as controls. Posts were cemented using Panavia 21 and $4 \mathrm{~mm}$ cylindrical composite cores were placed with a flat surface on the lingual aspect of the buildup. Following thermocycling of 5000 cycles, specimens were then tested along the flat surface in compression. Another set of specimens were prepared in the same manner except with fatigue cycling from 5-50 N performed prior to static loading. It was found that the highest ultimate force was with the stainless steel posts while the lowest ultimate force was with the fiber-reinforced posts. Only the fiber-reinforced posts had an ultimate breaking force less than the controls. Fracture was found to occur within the core buildup in most specimens. Tooth fracture occurred with the higher strength posts but did not occur with the polyethylene fiber-reinforced post specimens. The authors also found that fatigue cycling did not affect the strength of any posts, but thermocycling weakened the non-metal posts.

While this study provided a limited statistical analysis of the collected data, it clearly showed the mechanical differences between the tested post systems. As the strength of the post increased, the strength of the composite core increased. However, the effect of increased loading on the post-core complex was an increased incidence of tooth fracture. The incidence of tooth fracture was minimized with the fiber-reinforced posts despite the low breaking strength. This study underscores the variability of the load-to-failure depending on the post system used. Also significant was that the load-to-failure of the controls without post placement was similar to the polyethylene fiber-reinforced post systems.

Hsu et. al. (2002) determined how the bonding of a composite core would affect the failure of teeth restored with complete crowns. ${ }^{45}$ Using ten maxillary central incisors, canal spaces were prepared to $8 \mathrm{~mm}$ with a diameter of $1.25 \mathrm{~mm}$. A $1 \mathrm{~mm}$ wide circumferential 
shoulder in dentin was placed and the specimens were mounted in aluminum cylinders with autopolymerizing resin. In the bonded core group, stainless steel Paraposts were cemented using Scotchbond Multipurpose Plus with RelyX ARC cement and a self-curing composite core was then bonded to the tooth surface. In the unbonded core group, the coronal surface was not etched or bonded prior to composite core buildup. The teeth were then prepared to a height of 7 $\mathrm{mm}$ with a $1 \mathrm{~mm}$ long ferrule and impressed for gold crowns. The crowns were fabricated using a waxing jig and were cemented using zinc phosphate cement. Specimens were loaded $1 \mathrm{~mm}$ from the incisal edge with $4 \mathrm{~kg}$ at $280 \mathrm{cycles} / \mathrm{min}$. Failure was defined as propagation of a crack in or around the crown luting cement layer as evidenced by a strain gauge. The five unbonded core samples failed at an average cycle count of $62 \pm 31$ while the bonded core samples had cyclic load counts ranging from one sample of 19,880 to the other four having counts of over 100,000 . Bonding of a composite core to dentin prior to crown cementation provided stronger crown retention under fatigue loading.

It has been shown in previous studies that the angle of loading makes a significant difference in the fracture resistance of post-and-core specimens. ${ }^{38,39}$ In this study, the angle of loading was not presented. Furthermore, crowns were not adhesively cemented to the tooth or core and only a small ferrule was placed, thereby neglecting other possible retentive features that could have aided the non-bonded core group. However, this study presents a restorative scenario that emphasizes the importance of composite core bonding in the integrity of a post-and-core complex. It is possible that small differences in core bonding can lead to large differences in failure rate of a crowned post-and-core tooth.

In a comparative study, Reagan et. al. (1999) cyclic loaded selected post-and-core systems to determine differences in fatigue failure. ${ }^{46}$ Post-and-core systems did not have crowns placed since previous research has shown satisfactory post-and-core strengths with a sufficient crown ferrule. Instead, specimens were tested with no ferrule, analogous to a clinical situation where crown lengthening is not desirable or possible. Fifty mandibular premolars were decoronated $15 \mathrm{~mm}$ from the root apex and the canals were instrumented. Post spaces were prepared to $10 \mathrm{~mm}$ in length with a $1.25 \mathrm{~mm}$ diameter according to manufacturer instructions. Roots were mounted and surveyed so that the coronal tooth surface was parallel to the mounting ring. Posts were cemented with zinc phosphate cement and cores fabricated using a copper band 
adapted to the specimens. Two different metal posts and two different core materials (amalgam, Titanium-reinforced composite) were used in the study to make four pre-fabricated post groups. The cores were not bonded to the tooth structure. Cores were reduced in height to $5 \mathrm{~mm}$ and prepared with a $1.2 \mathrm{~mm}$ shoulder. A fifth test group was created by fabricating cast post and cores with similar dimensions as other groups. Cyclic loading was then performed at $4.66 \mathrm{~Hz}$ with $10 \mathrm{lbs}$ at a $90^{\circ}$ angle, $1 \mathrm{~mm}$ above tooth structure on the core. Using a transducer and computer to acquire the data, failure of the post and core was arbitrarily established as a lateral movement of the core of $63.5 \mu \mathrm{m}$ or more. The results indicated that there was no difference in resistance to cyclic loading by the five different post-and-core systems tested. In addition, the data showed great variability in the number of cycles to failure with large standard deviations.

It is likely that the lack of core bonding to the tooth or post negated the effects of the core on the fatigue failure of the systems tested. In order to show differences between post systems, it seems prudent to use an adhesive cement system that will provide better resistance to fatigue failure. This study showed that use of a metal post may provide sufficient resistance to lateral forces regardless of the core material used.

\section{REFERENCES}

1. Fredriksson M, Astback J, Pamenius M, Arvidson K. A retrospective study of 236 patients with teeth restored by carbon fiber-reinforced epoxy resin posts. J Prosthet Dent 1998; 80:151-7.

2. Saupe W, Gluskin A, Radke R. A comparative study of fracture resistance between morphologic dowel and cores and a resin-reinforced dowel system in the intraradicular restoration of structurally compromised roots. Quintessence Int 1996; 27:483-491.

3. Ferrari M, Vichi A, Mannocci F, Mason P. Retrospective study of the clinical performance of fiber posts. Am J Dent 2000; 13:9B-13B.

4. Ferrari M, Vichi A, Garcia-Godoy F. Clinical evaluation of fiber-reinforced epoxy resin posts and cast post and cores. Am J Dent 2000; 13:15B-18B.

5. Mannocci F, Ferrari M, Watson T. Microleakage of endodontically treated teeth restored with fiber posts and composite cores after cyclic loading: A confocal microscopic study. J Prosthet Dent 2001; 85:284-91. 
6. Ferrari M, Mannocci F. A 'one-bottle' adhesive system for bonding a fibre post into a root canal: an SEM evaluation of the post-resin interface. Int Endond J 2000; 33:397400.

7. Mannocci F, Innocenti M, Ferrari M, Watson T. Confocal and scanning electron microscopic study of teeth restored with fiber posts, metal posts, and composite resins. J Endodont 1999; 25:789-794.

8. Vichi A, Grandini S, Ferrari, M. Comparison between two clinical procedures for bonding fiber posts into a root canal: a microscopic investigation. J Endodont 2002; 28:355-60.

9. Stockton L. Factors affecting retention of post systems: a literature review. J Prosthet Dent 1999; 81:380-5.

10. Duncan J, Pameijer C. Retention of parallel-sided titanium posts cemented with six luting agents: an in vitro study. J Prosthet Dent 1998; 80:423-8.

11. Cohen B, Pagnillo M, Newman I, Musikant B, Deutsch A. Retention of three endodontic posts cemented with five dental cements. J Prosthet Dent 1998; 79:520-5.

12. Love R, Purton D. Retention of posts with resin, glass ionomer and hybrid cements. J Dent 1998; 599-602.

13. Drummond J. In vitro evaluation of endodontic posts. Am J Dent 2000; 13:5B-8B.

14. Stockton L, Williams P. Retention and shear bond strength of two post systems. Oper Dent 1999; 24:210-6.

15. Gallo J, Miller T, Xu X, Burgess J. In vitro evaluation of the retention of composite fiber and stainless steel posts. J Prosthodont 2002; 11:25-9.

16. El-mowafy O, Milenkovic M. Retention of paraposts cemented with dentin-bonded resin cements. Oper Dent 1994; 19:176-182.

17. Nissan J, Dmitry Y, Assif D. The use of reinforced composite resin cement as compensation for reduced post length. J Prosthet Dent 2001; 86:304-8.

18. Cohen B, Condos S, Musikant B, Deutsch A. Retention properties of a split-shaft threaded post: cut at different apical lengths. J Prosthet Dent 1992; 68:894-8.

19. Hagge M, Wong R, Lindemuth J. Effect of dowel space preparation and composite cement thickness on retention of a prefabricated dowel. J Prosthodont 2002; 11:19-24.

20. Love R, Purton D. The effect of serrations on carbon fibre posts - retention within the root canal, core retention, and post rigidity. Int J Prosthodont 1996; 9:484-8. 
21. Purton D, Love R. Rigidity and retention of carbon fibre versus stainless steel root canal posts. Int Endodont J 1996; 29:262-5.

22. Leary J, Aquilino S, Svare C. An evaluation of post length within the elastic limits of dentin. J Prosthet Dent 1987; 57(3):277-81.

23. Isidor $\mathrm{F}$, Odman $\mathrm{P}$, Brondum K. Intermittent loading of teeth restored using prefabricated carbon fiber posts. Int J Prosthodont 1996; 9:131-6.

24. Mendoza D, Ealde W, Kahl E, Ho R. Root reinforcement with a resin-bonded preformed post. J Prosthet Dent 1997; 78:10-15.

25. Jiménez, M. Fracture resistance and mode of failure of endodontically treated teeth restored with fiber reinforced posts. 2001. Masters of Science Thesis in Restorative Dentistry, The University of Michigan School of Dentistry, Ann Arbor, MI.

26. De Rijk W. Removal of fiber posts from endodontically treated teeth. Am J Dent 2000; 13:19B-21B.

27. Torbjorner A, Karlsson S, Syverud M, Hensten-Pettersen A. Carbon fiber reinforced root canal posts - mechanical and cytotoxic properties. Eur J Oral Sci 1996; 104:605611.

28. Mannocci F, Sherriff M, Watson T. Three-point bending test of fiber posts. J Endodont $2001 ; 27: 758-761$.

29. Purton D, Payne J. Comparison of carbon fiber and stainless steel root canal posts. Quintessence Int 1996; 27:93-7.

30. Asmussen E, Peutzfeldt A, Heitmann T. Stiffness, elastic limit, and strength of newer types of endodontic posts. J Dent 1999; 27:275-8.

31. Dietschi D, Romelli M, Goretti A. Adaptation of adhesive posts and cores to dentin after fatigue testing. Int J Prosthodont 1997:10:498-507.

32. Isidor F, Brondum K, Ravnholt G. The influence of post length and crown ferrule length on the resistance to cyclic loading of bovine teeth with prefabricated titanium posts. Int $\mathbf{J}$ Prosthodont 1999; 12:78-82.

33. King P, Setchell D. An in vitro evaluation of a prototype CFRC prefabricated post developed for restoration of pulpless teeth. J Oral Rehab 1990:17:599-609.

34. Martinez-Insua A, Da Silva L, Rilo B, Santana U. Comparison of the fracture resistances of pulpless teeth restored with a cast post and core or carbon-fiber post with a composite core. J Prosthet Dent 1998; 80:527-532. 
35. Sidoli G, King P, Setchell D. An in vitro evaluation of a carbon fiber-based post and core system. J Prosthet Dent 1997; 78:5-9.

36. Rosentritt M, Furer C, Behr M, Lang R, Handel G. Comparison of in vitro fracture strength of metallic and tooth-coloured posts and cores. J Oral Rehabil 2000; 27:595601.

37. Sirimai S, Riis D, Morgano S. An in vitro study of the fracture resistance and the incidence of vertical root fracture of pulpless teeth restored with six post-and-core systems. J Prosthet Dent 1999; 81:262-9.

38. Pegoretti A, Fambri, L, Zappini G, Bianchetti M. Fine element analysis of a glass fibre reinforced composite endodontic post. Biomaterials 2002; 23:2667-2682.

39. Yang H, Lang L, Molina A, Felton, D. The effects of dowel design and load direction on dowel-and-core restorations. J Prosthet Dent 2001; 85:558-67.

40. Akkayan B. Gulmez T. Resistance to fracture of endodontically treated teeth restored with different post systems. J Prosthet Dent 2002; 87:431-7.

41. Mollersten L, Lockowandt P, Linden L. A comparison of strengths of five core and postand-core systems. Quintessence Int 2002; 33:140-9.

42. Huysmans M, Peters M, Plasschaert A, Vander Varst P. Failure characteristics of endodontically treated premolars restored with a post and direct restorative material. Int Endodont J 1992; 25:121-9.

43. Cormier C, Burns D, Moon P. In vitro comparison of the fracture resistance and failure mode of fiber, ceramic, and conventional post systems at various stages of restoration. J Prosthodont 2001; 10:26-35.

44. CRA Journal. Which post has highest strength? Comparison of 7 Posts. www.cranews.com/newsletter/highlights/1998/98-11/posts/index.htm. November 1998.

45. Hsu Y, Nicholls J, Phillips K, Libman W. Effect of core bonding on fatigue failure of compromised teeth. Int J Prosthodont 2002; 15:175-8.

46. Reagan S, Fruits T, Van Brunt C, Ward C. Effects of cyclic loading on selected postand-core systems. Quintessence Int 1999; 30:61-7. 


\section{PRELIMINARY STUDY}

A pilot study was performed to determine the feasibility of the research plan. The aim of the pilot study was to test the proposed methodology and variability of the experimental setup.

Nine single-rooted maxillary or mandibular premolar teeth were selected to have similar size and shape and were then sectioned at the buccal CEJ with a rotating sand disk. They were then endodontically treated using successive file sizes to within $1 \mathrm{~mm}$ of the apex at a master file size of 35 . The canals were irrigated with $5.25 \% \mathrm{NaOCl}$ and stored in a $100 \%$ humidity environment. Post spaces of $1.5 \mathrm{~mm}$ diameter were drilled to lengths of either $3 \mathrm{~mm}, 6 \mathrm{~mm}$, or 9 $\mathrm{mm}$ from the CEJ using the drills included with the FibreKor Post kit (Pentron Tech., Wallingford, CT). The post spaces were cleaned using a chlorhexidine solution (Consepsis; Ultradent Inc., Sandy, UT) and rinsed thoroughly with water. A $1.5 \mathrm{~mm}$ diameter FibreKor post was shortened for a $3 \mathrm{~mm}$ coronal extension $(6 \mathrm{~mm}, 9 \mathrm{~mm}$, and $12 \mathrm{~mm}$ total post lengths) and cemented using a dual-cured resin cement kit (Cement-It; Pentron Tech, Wallingford, CT) following manufacturer's instructions. Excess cement was cleaned up coronally and the post cement light cured for 40 seconds. The setup of the post lengths tested is shown in Table 2 .

Table 2: Experimental Setup of Posts Tested at Respective Lengths.

\begin{tabular}{|l|c|c|c|c|}
\hline \multicolumn{1}{|c|}{ Post type } & $\begin{array}{c}\text { Number of } \\
\text { samples }\end{array}$ & $\begin{array}{c}\text { Root post } \\
\text { length }\end{array}$ & $\begin{array}{c}\text { Coronal post } \\
\text { length }\end{array}$ & $\begin{array}{c}\text { Root:Coronal } \\
\text { post length ratio }\end{array}$ \\
\hline FibreKor $1.5 \mathrm{~mm}$ & 3 & $3 \mathrm{~mm}$ & $3 \mathrm{~mm}$ & 1.0 \\
\hline FibreKor $1.5 \mathrm{~mm}$ & 3 & $6 \mathrm{~mm}$ & $3 \mathrm{~mm}$ & 2.0 \\
\hline FibreKor $1.5 \mathrm{~mm}$ & 3 & $9 \mathrm{~mm}$ & $3 \mathrm{~mm}$ & 3.0 \\
\hline
\end{tabular}

To fabricate the composite core, a plastic stent was used with an inner diameter, outer diameter, and height of $1.5,3.5$, and $8 \mathrm{~mm}$, respectively. The inner opening of the stent was situated around the post so that the outer diameter of the stent was $1 \mathrm{~mm}$ from the post. With the stent secured, a clear PVS material (Memosil 2; Heraeus Kulzer Inc., South Bend, IN) was injected around the outer surface of the stent and extended below the CEJ to form an undercut impression of the root. The PVS was built up to give approximately 6-8 $\mathrm{mm}$ of height to allow for overfill of the core. Once set, the plastic stent was removed, leaving the PVS registration in place and a $1 \mathrm{~mm}$ core space circumferentially around the post. The PVS registration was removed, and the coronal tooth was then etched for 15 seconds and rinsed thoroughly. Bonding 
agent was placed on the tooth and post and cured for 20 seconds. The PVS registration was then placed back on the tooth. A composite core material (SuperCure; Centrix Inc., Shelton, CT) was injected around the post in the space created by the PVS registration. The core was built to a height of approximately $6 \mathrm{~mm}$ and then light cured for 40 seconds. The PVS registration was then cut and peeled off the core and tooth to leave the core undisturbed. The core was then cured for another 40 seconds. The core was then finished to a $4 \mathrm{~mm}$ coronal height.

A control group was mechanically tested with a composite core only. There was no post included in the complex. Specimens were prepared as previously described. In order to orient the core, a $1.5 \mathrm{~mm}$ post was initially placed in the canal to allow for the plastic core stent to be placed. Once the stent was placed, clear PVS was injected around the outer surface of the stent and extended below the CEJ to form an undercut impression of the root. Once set, the plastic stent was removed, leaving the PVS registration in place and a $3.5 \mathrm{~mm}$ core space centered around the hollow post space. A cotton pellet was used to plug the post space to the coronal extent. Specimen preparation continued as previously described.

Specimens were then mounted $1 \mathrm{~mm}$ below the CEJ in a copper cylindrical mold using yellow stone to allow for mechanical testing. They were then stored in $100 \%$ humidity for 24 hours prior to testing. The samples were tested at approximately a $90^{\circ}$ angle to the long-axis of the tooth-post complex and at a distance $1 \mathrm{~mm}$ from the end of the core using an Instron Universal Testing Machine. The crosshead speed was $0.5 \mathrm{~mm} / \mathrm{min}$. The load to failure was recorded as was the mode of failure. The results are shown in Table 3 and Figures 1 and 2.

Table 3: Pilot Study Load Values Using FibreKor Posts

\begin{tabular}{|c|c|c|c|}
\hline $\begin{array}{c}\text { Post length (in } \\
\text { root) }\end{array}$ & $\begin{array}{c}\text { Core-tooth } \\
\text { bond load (N) }\end{array}$ & Max. load (N) & $\begin{array}{c}\text { Site of initial } \\
\text { failure }\end{array}$ \\
\hline $0 \mathrm{~mm}$ (Control) & $30.66 \pm 17.66$ & N/A & $\begin{array}{c}\text { Core-tooth } \\
\text { debonding }\end{array}$ \\
\hline $3 \mathrm{~mm}$ & $24.67 \pm 4.04$ & $144.13 \pm 31.57$ & $\begin{array}{c}\text { Core-tooth } \\
\text { debonding }\end{array}$ \\
\hline $6 \mathrm{~mm}$ & $20.33 \pm 6.66$ & $156.16 \pm 30.02$ & $\begin{array}{c}\text { Core-tooth } \\
\text { debonding }\end{array}$ \\
\hline $9 \mathrm{~mm}$ & $22.00 \pm 8.49$ & $130.30 \pm 24.47$ & $\begin{array}{c}\text { Core-tooth } \\
\text { debonding }\end{array}$ \\
\hline
\end{tabular}




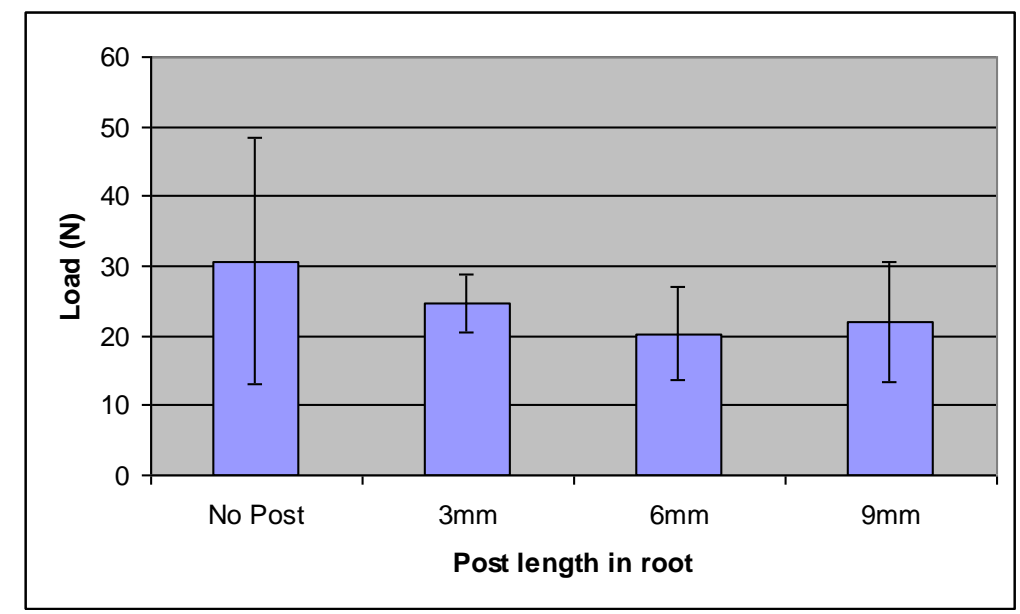

Figure 1: Effect of post length on core bond failure load (Pilot study)

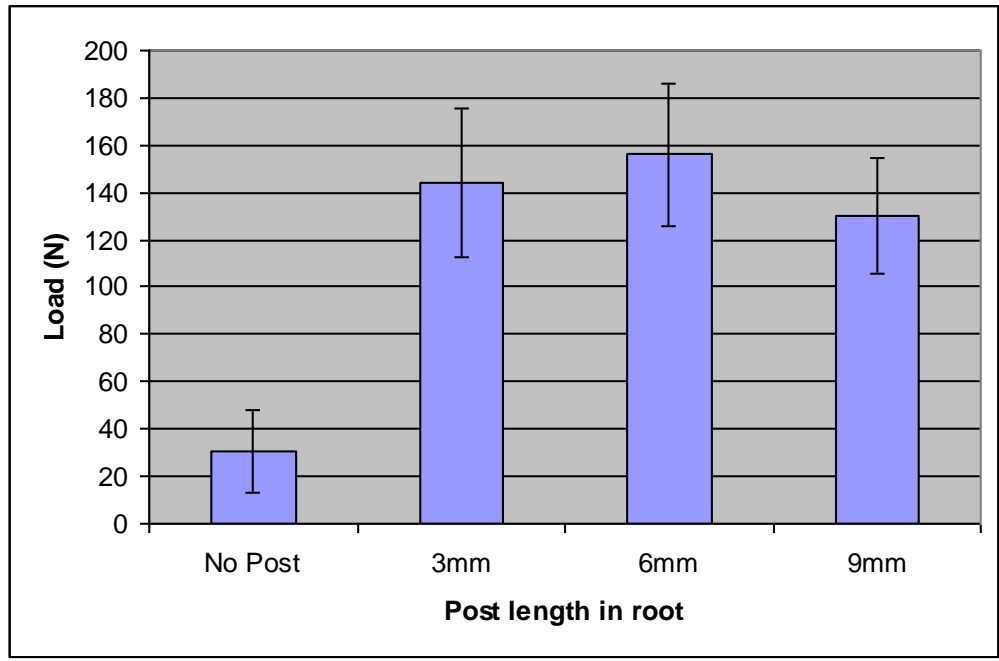

Figure 2: Effect of post length on maximum failure load (Pilot study)

In order to explain the results from the pilot study, it is important to establish the possibility for error in the testing setup. Given the results and standard deviation of specimens, it appears that the three post lengths tested could be equal in terms of core bond load. There are several possible explanations for the larger average load in the control group with no post compared to the groups with posts. It is possible that the post groups had contamination of the coronal bonding surface from resin cementing the posts, while the control group did not use resin cement. It is also possible that the solid composite core in the control group provided increased strength compared to having a post in the core. It was postulated that the mismatch in flexural moduli of the post and core could create an increased stress concentration at the bond interface. 
In the experimental setup, this stress concentration would be most likely exacerbated at the coretooth interface due to its orientation to the applied load.

During preparation and testing of specimens, there were no major obstacles encountered, but several changes will be made to the methodology to correct possible shortcomings.

Standardized drill sizes will be used for each post space. In groups with no posts, the post openings will then be closed with PVS material to prevent excess bonding in the post space. In addition, a dual-cure core material will be used, with a lower reported shrinkage than the light-cured composite used in the pilot study. The results from the pilot study provides evidence that the proposed research is feasible and will provide valid data. 


\title{
CHAPTER 2
}

\section{THE EFFECT OF POST TYPE AND LENGTH ON THE FRACTURE RESISTANCE OF ENDODONTICALLY TREATED TEETH}

\begin{abstract}
Objectives: The objective of this study was to compare the fracture resistance and mode of failure of endodontically treated teeth restored with three different post systems at two lengths, including two light-transmitting fiber-reinforced posts (Light Post and Snowlight) and a stainless steel post (Parapost XP).

Methods: $\quad$ Seventy human single-rooted premolars were endodontically treated and sectioned at the buccal CEJ. Teeth were randomly distributed into groups of ten and assigned to one of seven treatment groups. Three different pre-fabricated posts were cemented at either 5 or $10 \mathrm{~mm}$ into a post space and composite cores fabricated. A composite core group with no post served as a control. Samples were stored for 24 hours in $100 \%$ humidity at $37^{\circ} \mathrm{C}$ and were subsequently loaded at $90^{\circ}$ to the longitudinal axis until ultimate failure occurred. An initial failure load and mode of failure were also recorded.
\end{abstract}

Results: $\quad$ Statistical analysis of data using 2-way ANOVA revealed significant differences between groups, with post type and post length having an effect on initial failure load. Parapost XP samples had significantly higher initial and ultimate failure loads than Light Post or Snowlight samples at each of the two respective post lengths. The $10 \mathrm{~mm}$ post length produced a significantly higher load to failure than the $5 \mathrm{~mm}$ post length for initial failure, but not for ultimate failure. All $10 \mathrm{~mm}$ post length groups had initial failure loads significantly higher than the composite core control and all groups had ultimate failure loads significantly higher than the control. The highest average initial failure load was the Parapost XP at $10 \mathrm{~mm}(170.05 \pm 60.08$ $\mathrm{N})$ and the lowest was Snowlight at $5 \mathrm{~mm}(62.85 \pm 18.47 \mathrm{~N})$. Core debonding from the tooth interface was the mode of initial failure for all samples. Root fractures upon ultimate failure occurred in $25 \%$ of Parapost XP samples and no root fractures were found in any other group.

Significance: As dentists select more esthetic treatment options to restore endodontically treated teeth, the use of fiber-reinforced posts is becoming common. However, literature supporting their use is limited. One concern with these posts is their low stiffness and how it translates to support for a core and stress distribution within root dentin. The results of this study indicate that a stainless steel post may provide better support for a core than a glass or quartz fiber-reinforced post when a $90^{\circ}$ load is applied. A longer post may also provide better support for a core to prevent core debonding. The glass and quartz fiber-reinforced posts were not found to be significantly different from each other for providing fracture resistance at a $90^{\circ}$ load angle. 


\section{INTRODUCTION}

In the past, selection of a pre-fabricated post has largely been a decision between stainless steel and titanium, threaded and non-threaded, tapered and non-tapered. The advent of more advanced composite and ceramic materials has led to the development of a wide variety of non-metal posts, including fiber-reinforced posts. Glass and quartz fiber-reinforced posts can provide improved esthetics, especially when an all-ceramic crown is the final restoration. The use of fiber-reinforcement has a long history in dentistry, but it was not until 1990 that the first fiber-reinforced post was introduced. Fiber-reinforced posts have shown good clinical success up to 6 years in retrospective studies. ${ }^{(1-3)}$ However, clinical success may be a function of remaining tooth structure and post retention to prevent leakage within the canal. Resin cement with a bonding agent when placing a post may help to limit microleakage ${ }^{(4)}$ and increase retention of pre-fabricated posts. ${ }^{(5-10)}$ Nonetheless, the quality of bonding may diminish at greater apical post space depths ${ }^{(11,12)}$ and an increased post length may not provide any increase in predictable bonding area.

It has been suggested that a shorter post length may be used without loss of retention ${ }^{(10,}$ ${ }^{13,14)}$ and that serrations on a post may increase retention. ${ }^{(15)}$ On the other hand, when a ferrule cannot be placed, the post length may not have much effect on the overall strength of the postand-core. Instead, core debonding may be the primary mechanism of failure due to a lack of post bending resistance. ${ }^{(16)}$ For severely compromised roots, an adhesively bonded fiber post may provide improved fracture resistance compared to a metal post. This potential for resin bonding to reinforce remaining root structure has been shown to help account for a flared canal or poorly adapted post. ${ }^{(17-19)}$

Today, the fiber-reinforced posts can be separated into three main groups: carbon fiber, glass fiber and quartz fiber. The fiber content ranges from about 35-65\%, with a higher fiber content post typically having greater strength and stiffness. It has been shown in one study that a carbon fiber-reinforced post had comparable flexural modulus values as a stainless steel post. ${ }^{(20)}$ However, another study has shown glass fiber-reinforced posts to have lower strength than other types of fiber-reinforced posts ${ }^{(21)}$ and certain carbon fiber-reinforced posts to be less stiff than stainless steel posts. ${ }^{(22,23)}$ Clinically, this reduced stiffness may be beneficial to preventing catastrophic root fracture. Given an approximate modulus of elasticity of dentin to range from 
18.5-21.8 $\mathrm{GPa}^{(24)}$, the moduli of fiber-reinforced posts are closer to root dentin than metal posts. Many studies have tested this idea and have found that fiber-reinforced posts preserve the root in failure. $^{(25-30)}$ The difference in the mode of failure between fiber-reinforced posts and metal posts is clear. Less clear is whether fiber-reinforced posts actually provide adequate support for a core. Several authors have found fiber-reinforced posts provide less resistance to fracture during loading than cast metal or metal pre-fabricated posts. ${ }^{(25-27,29,30)}$ Flexure of a fiberreinforced post may shift the load to the composite core, causing premature failure in the core. $(25,27,29,31,32)$ This is of particular importance in clinical instances where little or no coronal tooth structure remains. Finite element analysis has indicated that blunt traumatic or transverse loading may concentrate stresses at the cervical aspects of a tooth ${ }^{(32-34)}$ and therefore places more load on the post.

It seems evident that the test conditions have a major influence on the fracture resistance and mode of failure of post-and-core systems. In fact, the use of a composite core has been shown to increase the resistance to fracture during loading. ${ }^{(35)}$ Also, differences in the stiffness properties of fiber-reinforced posts compared to metal posts may have greater significance with a load applied perpendicular to the longitudinal axis. To address this concern, the flexural modulus of each post system was determined to serve as a basis for the experimental design.

The purpose of this study was to compare the fracture resistance and mode of failure of endodontically treated teeth restored with composite cores and three different post systems at two lengths, including two light-transmitting fiber-reinforced posts (Light Post and Snowlight) and a stainless steel post (Parapost XP). 


\section{METHODS AND MATERIALS}

\section{Flexural modulus testing}

Although each manufacturer provides flexural modulus information on their respective post system, it was decided to test each post type to get an actual estimate of the flexural modulus. Five posts of either stainless steel (Parapost XP; Lot \#42024, Coltene/Whaledent Inc., Mahwah, NJ), quartz fiber-reinforced (Light Post; Lot \#0200005207, Bisco Inc., Schaumburg, IL), or glass fiber-reinforced (Snowlight; Lot \#LB051, Danville Materials, San Ramon, CA) were tested for flexural modulus using an Instron Series IX Automated Materials Testing System (Figure 1). The samples were loaded in 3-point bending with a $12 \mathrm{~mm}$ fixed width at a crosshead speed of $0.5 \mathrm{~mm} / \mathrm{min}$. The diameter of each post was recorded and the flexural modulus was calculated using the equation:

$$
\mathrm{E}_{\text {flex }}=4(\text { Slope })(\operatorname{Span})^{3} / 3(\pi)(\text { Diameter })^{4}
$$

where the slope is the loading curve in the elastic region of loading. The average flexural modulus and standard deviation of each post group was determined.

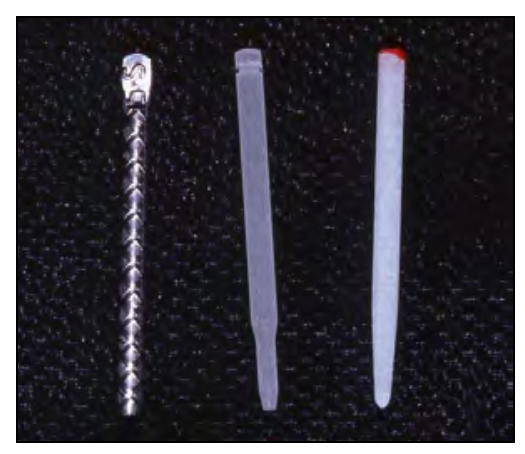

Figure 1: Parapost XP, Light Post and Snowlight posts.

\section{Preparation of samples}

A total of 70 recently extracted single-rooted human premolars with similar dimensions were selected for testing. The minimum root length was $13 \mathrm{~mm}$ from root apex to the buccal CEJ. The teeth were examined under a microscope to exclude any teeth with carious lesions, cracks, previous endodontic treatment, or restoration closer than $2 \mathrm{~mm}$ from the CEJ. The teeth were randomly assigned to the experimental groups with 10 teeth per group.

The teeth were sectioned at the buccal CEJ, finished with 600 grit SiC paper, and then stored in a $0.2 \%$ sodium azide solution. They were endodontically treated using a conventional 
step-back technique. The working length was established by subtracting $1 \mathrm{~mm}$ from the length of an ISO file size 10 at initial apical perforation. Canals were cleaned and shaped using rotary instrumentation to an ISO file size of 35 , and then were irrigated with sodium hypochlorite (5.25\%) and dried with paper points. Condensation with gutta-percha and non-eugenol sealer (AH Plus, Lot \#9905000956; Dentsply Int., York, PA) was then completed using a lateral condensation technique. Post spaces were prepared to either 5 or $10 \mathrm{~mm}$ in length and 0.055 " $(1.4 \mathrm{~mm})$ in diameter from the coronal extent of each tooth. During post space preparation, a dental surveyor was used to align the space at a $90^{\circ}$ angle to the coronal tooth floor. Next, a thin silicone film (Plasti-Dip, PlastiDip Int., Blaine, MN) was coated on the root to within $1 \mathrm{~mm}$ of the coronal floor to simulate a periodontal ligament space (Figure 2). The thickness of the film was uniformly 0.1-0.2 $\mathrm{mm}$ as measured using a mechanical depth gauge.

The posts used were either Parapost XP, Light Post, or Snowlight as described previously, each with a diameter of 0.055 " $(1.4 \mathrm{~mm})$. Both the Light Post and Snowlight posts are described as "light-transmitting" by the manufacturers and are designed to allow light curing to reach the apical end during cementation. The root extension of the posts were 5 or $10 \mathrm{~mm}$ with a coronal extension fixed at $3 \mathrm{~mm}$. This corresponded to a root/crown post length ratio of 1.67 or 3.33 , respectively. A composite core control was used whereby no post was placed to establish the effect of bonding a composite core to tooth alone. The experimental design is shown in Table 1.

Table 1: Experimental Design for Testing.

\begin{tabular}{|c|c|c|c|c|}
\hline $\begin{array}{c}\text { Group } \\
(\mathbf{N}=10)\end{array}$ & Post type & $\begin{array}{c}\text { Post } \\
\text { Diameter }\end{array}$ & $\begin{array}{c}\text { Post } \\
\text { length } \\
\text { (in root) }\end{array}$ & $\begin{array}{c}\text { Root/Crown } \\
\text { post ratio }\end{array}$ \\
\hline 1 & Parapost XP (Stainless Steel) & $1.4 \mathrm{~mm}$ & $10 \mathrm{~mm}$ & 3.33 \\
\hline 2 & Parapost XP (Stainless Steel) & $1.4 \mathrm{~mm}$ & $5 \mathrm{~mm}$ & 1.67 \\
\hline 3 & Light Post (Quartz fiber-reinforced) & $1.4 \mathrm{~mm}$ & $10 \mathrm{~mm}$ & 3.33 \\
\hline 4 & Light Post (Quartz fiber-reinforced) & $1.4 \mathrm{~mm}$ & $5 \mathrm{~mm}$ & 1.67 \\
\hline 5 & Snowlight (Glass fiber-reinforced) & $1.4 \mathrm{~mm}$ & $10 \mathrm{~mm}$ & 3.33 \\
\hline 6 & Snowlight (Glass fiber-reinforced) & $1.4 \mathrm{~mm}$ & $5 \mathrm{~mm}$ & 1.67 \\
\hline 7 & Control (Composite core only) & NA & NA & NA \\
\hline
\end{tabular}


The posts were sectioned to the corresponding length required ( $8 \mathrm{~mm}$ or $13 \mathrm{~mm}$ total) and tapered or non-cylindrical ends removed so that only parallel cylindrical posts remained. The Parapost XP posts had the flat coronal head removed, while the Light Post and Snowlight posts had the tapered apical portions removed. The posts were then cleaned thoroughly with an alcohol wipe. To standardize samples, core formers were custom made for each individual tooth as follows:

1) Post (1.4 mm diameter) placed into post space for alignment purposes.

2) Prefabricated black Delrin ${ }^{\circledR}$ cylindrical sleeve with $3.4 \mathrm{~mm}$ outer $/ 1.4 \mathrm{~mm}$ inner dia. $\mathrm{x} 8$ $\mathrm{mm}$ height placed around post, flush with tooth (Figure 3).

3) Translucent vinylpolysiloxane material (Star VPS ClearBite; Danville Materials, San Ramon, CA) injected around Delrin ${ }^{\circledR}$ sleeve and undercut root structure to create custom core former (Figure 4).

4) Delrin ${ }^{\circledR}$ sleeve and post removed, leaving the clear PVS core former (Figure 5).

5) Core former removed from tooth and orientation marked as related to tooth.

Following fabrication of custom core formers, the tooth surface and post space were etched for 15 seconds with 37\% phosphoric acid (Uni-etch; Bisco Inc., Schaumburg, IL). The etchant was rinsed off for 15 seconds with water, then lightly air dried. Post spaces were dried using paper points but left moist. Dual-cured bonding agent (ParaPost Adhesive Conditioner A + B; Coltene/Whaledent Inc., Mahwah, NJ), was then applied to the post surface using a microbrush and light cured for 20 seconds. The bonding agent was then applied to the tooth surface and post space using an endodontic microbrush and allowed to sit for 30 seconds according to manufacturers instructions. Excess bonding agent within the post space was absorbed using paper points. Next, a dual-cure composite core material (ParaPost ParaCore automix, Lot \#LE726; Coltene/Whaledent Inc., Mahwah, NJ) was injected into the post space and lentulospiral used to spread the material. The post was slowly seated to place within the post space and held for 5 seconds to allow for reduction in cementation pressure. Any excess post cement material was cleaned around the coronal post periphery. The translucent custom core former was then reseated around the tooth creating a core space around a centered post. The dual-cure composite core material was then injected into the core space surrounding the post to a height of approximately $6 \mathrm{~mm}$ (Figure 6). The core was then light cured for 40 seconds from the 


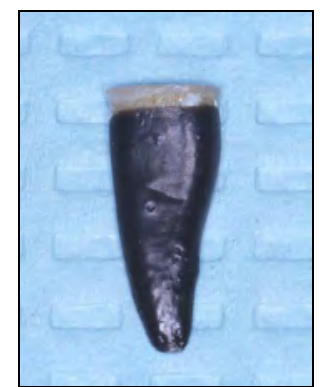

Figure 2: Silicone simulated periodontal ligament space (in black).

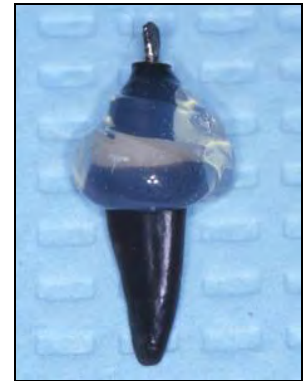

Figure 4: Translucent VPS core former using post and prefabricated Delrin ${ }^{\circledR}$ sleeve.

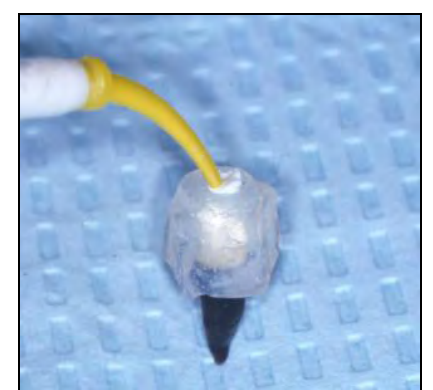

Figure 6: Post cemented and core material injected into space to create core.

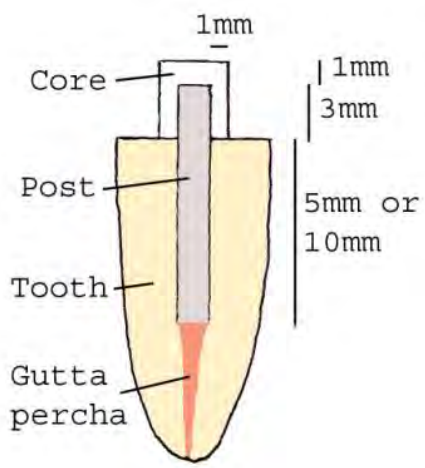

Figure 8: Schematic diagram of post-and-core samples.

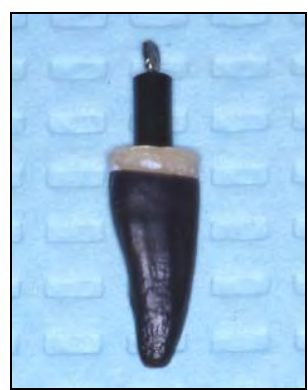

Figure 3: Prefabricated Delrin ${ }^{\circledR}$ sleeve and alignment post

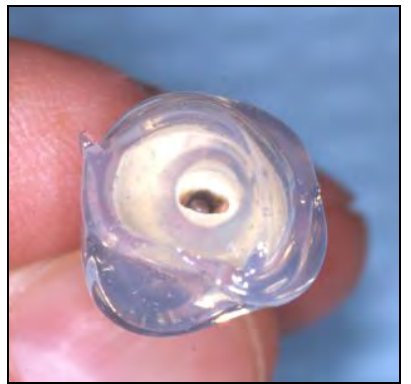

Figure 5: Core and post space after prefabricated Delrin ${ }^{\circledR}$ sleeve removed.

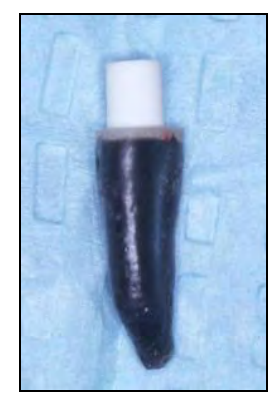

Figure 7: Core former removed and core finished to $4 \mathrm{~mm}$ height.

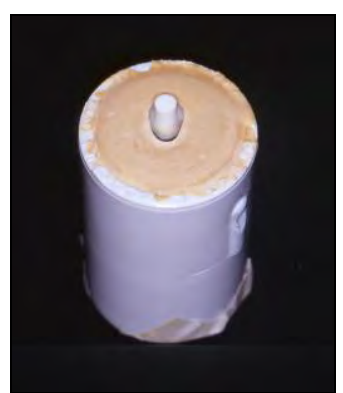

Figure 9: Sample mounted $1 \mathrm{~mm}$ from CEJ. 
occlusal surface. Following a 5 minute set time, the translucent core former was removed from the tooth, leaving the remaining cemented post-and-core. The samples were then cured for 20 seconds each from both the buccal and lingual of the core. The cores were finished using medium and fine diamonds to a height to $4 \mathrm{~mm}$ from the coronal tooth floor (Figure 7). This left the extension of the post $1 \mathrm{~mm}$ from the occlusal surface, and $1 \mathrm{~mm}$ from the axial surface as shown in a schematic (Figure 8).

The control group of composite core samples did not have posts cemented. Instead, the translucent core formers were custom fabricated as described previously. The post spaces were then filled with a vinylpolysiloxane impression material to the coronal surface. The translucent custom core former was then reseated around the tooth, leaving an open core space without a post. Following a 15 second phosphoric acid etch and water rinsing, the dual-cured bonding agent was then applied to the tooth surface, allowed to sit for 30 seconds, and light cured for 20 seconds. Dual-cured composite core material was injected into the core space to a height of approximately $6 \mathrm{~mm}$ and light cured for 40 seconds from the occlusal surface. After a 5 minute set time, cores were further cured for 20 seconds from both the buccal and lingual and finished using medium and fine diamonds to a height of $4 \mathrm{~mm}$ from the coronal tooth floor.

After fabrication, the samples were mounted in $11 / 8$ " PVC pipe rings using yellow dental stone. Samples were mounted to $1 \mathrm{~mm}$ from the buccal CEJ and were aligned using a dental surveyor so that the long axis of the sample was parallel to the mounting ring (Figure 9). The samples were stored in $100 \%$ humidity at $37^{\circ} \mathrm{C}$ for 24 hours prior to mechanical testing.

\section{Testing of samples}

Following storage, the samples were positioned in a mounting device so that the longitudinal axis was perpendicular to the load direction. In addition, the teeth were positioned with the buccal surface as the site of loading. The teeth were then loaded from the core at $90^{\circ}$ to the long axis at $3 \mathrm{~mm}$ from the tooth-core interface, corresponding to the coronal extension of the post. The test angle was selected in order to eliminate oblique forces on the post-core complex and to load in the direction most vulnerable to failure. An Instron Universal Testing Machine with a $1 \mathrm{~mm}$ diameter rounded loading plunger was used to load the samples at a crosshead speed of $0.5 \mathrm{~mm} / \mathrm{min}$. The samples were loaded until catastrophic failure occurred and the ultimate failure load was recorded. In addition, the mode of failure was recorded as 
either root fracture, composite core fracture, post fracture, or any interface debonding. Catastrophic failure was designated as the point at which samples were no longer intact. Subcatastrophic failure occurring prior to the ultimate failure load was noted during the load sequence. Once ultimate failure occurred, the load curve raw data for each sample was examined and any drop in loading was recorded as a sub-catastrophic failure event. The first sub-catastrophic failure was designated as the initial failure of a sample.

Following mechanical testing, the samples were removed from the mounting and teeth were radiographed using F-speed radiographic film to determine if post pullout or post-core debonding had occurred. Post pullout was evident as separation of the post from the endodontic fill at the apical extent of the post space. Post-core debonding was radiographically evident as separation of the post from the core material at the occlusal extent. Finally, a 20x light microscope was used to take photographs of samples and verify the mode of failure.

\section{$\underline{\text { Data analysis and statistics }}$}

The sample data was combined in each group and an average initial failure load and ultimate failure load were calculated. In addition, the mode-of-failure was noted as it related to the ultimate failure load. To calculate the maximum bending stress for the post-and-core configuration, the following equation was used:

$$
\sigma_{\max }=M \times \quad y / \mathrm{I}
$$

where $M=$ the applied bending moment acting on a cross-section, $y=$ the distance from the point of loading to the tooth interface of the post-and-core, and I = the moment of inertia about the longitudinal axis. In the case of the cylindrical post-and-core, $I=\pi r^{4} / 4$. The equation is used to determine the maximum bending or flexural stress on a cross-section of a beam, similar to the conditions tested. For the purposes of the test setup, $r=0.0017 \mathrm{~m}, \mathrm{M}=$ (Load applied) (0.0017 $\mathrm{m})$, and $\mathrm{y}=0.003 \mathrm{~m}$, simplifying the above equation to:

$$
\sigma_{\max }=777471.7 \times \text { Load (in Newtons) }
$$

During loading, the superior portion of the post-and-core has a maximum bending stress at the tooth-core interface in tension, while the inferior portion is at maximum bending stress in compression. 
Once compiled, the data was analyzed with SAS v8.2 using 2-way ANOVA with a Bonferroni adjustment with post type and post length as variables and the initial or ultimate load as the outcome. A 1-way ANOVA using a post-hoc t-test with a Bonferroni adjustment was used to compare group means including the composite core control group to find significant differences. 


\section{RESULTS}

Table 2 shows the average diameter and flexural modulus of the pre-fabricated posts as tested. The Parapost XP posts had the smallest average diameter at $1.30 \mathrm{~mm}$ and the highest flexural modulus at $132.1 \mathrm{GPa}$. The two light-transmitting fiber-reinforced posts had similar diameters and flexural moduli. The results from the mechanical testing indicate that the stainless steel post had approximately a three-fold higher flexural modulus or resistance to bending.

Table 2: Average Diameter and Flexural Modulus for Different Post Types.

\begin{tabular}{|l|c|c|}
\hline Post type & $\begin{array}{c}\text { Ave. diameter } \\
(\mathbf{m m})\end{array}$ & $\begin{array}{c}\text { Ave. flexural } \\
\text { modulus (GPa) }\end{array}$ \\
\hline Parapost XP & 1.30 & 132.1 \\
\hline Light Post & 1.38 & 39.1 \\
\hline Snowlight & 1.39 & 38.2 \\
\hline
\end{tabular}

During mechanical loading of samples, it was determined that an initial failure of the post-and-core was occurring, by visual observation of separation of the core at the tooth interface. Upon review of the load data, the initial failure load was designated as the first drop in the load values (Figure 10). For most samples, this drop in load value corresponded with core debonding at the superior aspect of the core-tooth interface. For some samples, there was no initial failure and a drop in load value did not occur until catastrophic failure of the post-andcore. A graphical representation of the average initial failure load is shown in Figure 11. The corresponding group numerical averages, standard deviations, and significant differences after using 1-way ANOVA and a Bonferroni adjustment are shown in Table 3. In addition, the mean maximum failure bending stress and standard deviations are calculated for each group. The highest average initial failure load was found with the Parapost XP $10 \mathrm{~mm}$ group (170.05 \pm $60.08 \mathrm{~N})$, followed by the Light Post $10 \mathrm{~mm}$ group $(123.29 \pm 46.64 \mathrm{~N})$. These groups had significantly higher loads compared to all others. The composite core control (with no post) had the lowest initial failure load $(40.24 \pm 9.52 \mathrm{~N})$ but was not statistically different than either the Snowlight $10 \mathrm{~mm}$ or $5 \mathrm{~mm}$ groups or the Light Post $5 \mathrm{~mm}$ group.

The post type and post length variable effects on the initial failure loads using 2-way ANOVA and a Bonferroni adjustment are shown in Table 4. The type of post placed $(\mathrm{p}<0.0001)$ and the length within the root $(p=0.0003)$ significantly influenced the initial failure loads of the 
groups. The combination of the type of post and the length was not significant $(\mathrm{p}=0.0959)$. Comparing grouped data in Table 5, the Parapost XP groups had significantly higher initial failure loads than either the Light Post or Snowlight groups. In addition, the $10 \mathrm{~mm}$ post length groups had significantly higher initial failure loads than the $5 \mathrm{~mm}$ post length groups.

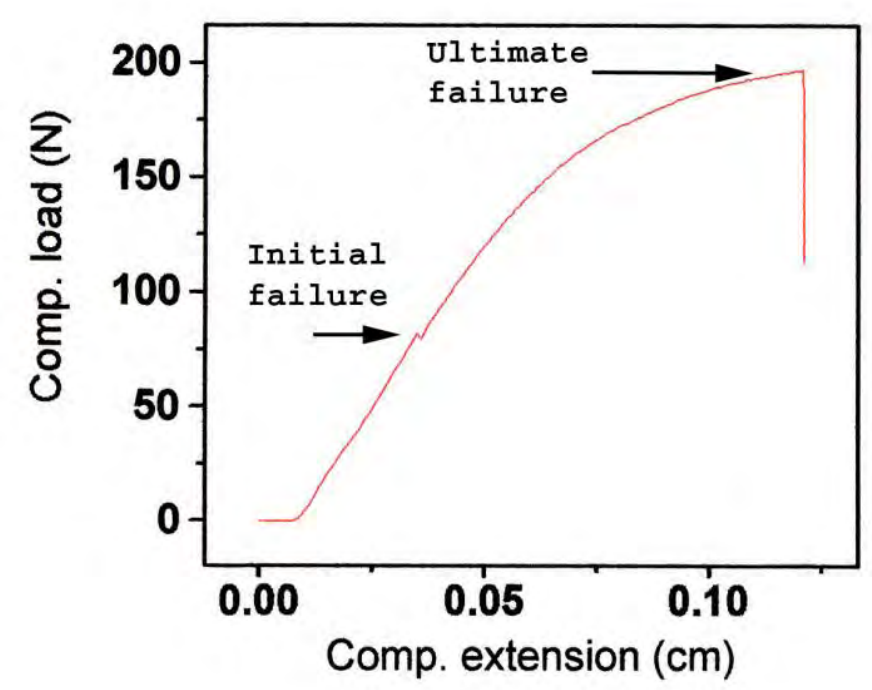

Figure 10: Typical loading curve for sample showing initial failure and ultimate failure.

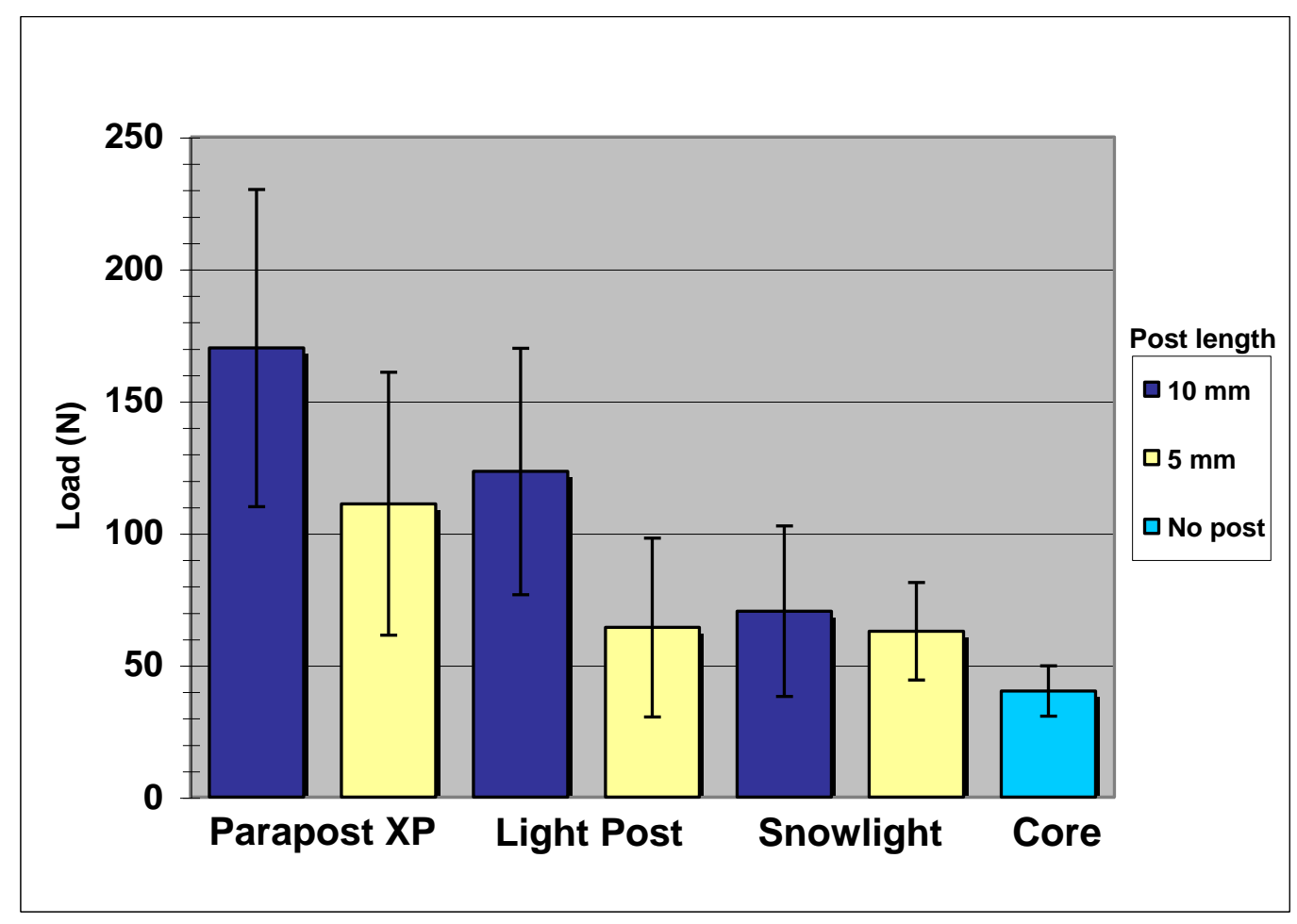

Figure 11: Average initial failure load based on post type and post length 
Table 3: Group Differences of Least Squares Means Using 1-way ANOVA for Initial Failure Load After a Bonferroni Adjustment

\begin{tabular}{|c|c|c|c|c|}
\hline Post Type & Length & $\begin{array}{c}\text { Mean failure load } \\
\pm \text { SD }(N)\end{array}$ & $\begin{array}{c}\text { Mean max. failure } \\
\text { bending stress } \pm \text { SD } \\
(\mathrm{MPa})\end{array}$ & $\begin{array}{c}\text { Sig. } \\
\text { Differences } \\
(\mathbf{p}<\mathbf{0 . 0 5}) \\
\end{array}$ \\
\hline Parapost XP & $10 \mathrm{~mm}$ & $170.05 \pm 60.08$ & $132.21 \pm 46.71$ & \\
\hline Light Post & $10 \mathrm{~mm}$ & $123.29 \pm 46.64$ & $95.85 \pm 36.26$ & \\
\hline Parapost XP & $5 \mathrm{~mm}$ & $111.08 \pm 49.84$ & $86.36 \pm 38.75$ & \\
\hline Snowlight & $10 \mathrm{~mm}$ & $70.43 \pm 32.26$ & $54.76 \pm 25.08$ & \\
\hline Light Post & $5 \mathrm{~mm}$ & $64.25 \pm 33.83$ & $49.95 \pm 26.30$ & \\
\hline Snowlight & $5 \mathrm{~mm}$ & $62.85 \pm 18.47$ & $48.86 \pm 14.36$ & \\
\hline Core (no post) & $\mathrm{N} / \mathrm{A}$ & $40.24 \pm 9.52$ & $31.28 \pm 7.40$ & \\
\hline
\end{tabular}

Note: Bars between groups indicate no significant difference

Statistics were derived from $t$-test with $63 \mathrm{DF}$

Table 4: 2-way ANOVA for Initial Failure Load Based on Post Type and Post Length

\begin{tabular}{|l|c|c|c|c|}
\hline Effect & Num DF & Den DF & F Value & P value \\
\hline Post & 2 & 54 & 15.55 & $<0.0001$ \\
\hline Length & 1 & 54 & 14.61 & 0.0003 \\
\hline Post x Length & 2 & 54 & 2.45 & 0.0959 \\
\hline
\end{tabular}

Table 5: Post Type and Length Differences of Least Squares Means Using 2-way ANOVA for Initial Failure Load After a Bonferroni Adjustment

\begin{tabular}{|c|c|c|c|c|}
\hline Post Type or Length & Post Type or Length & DF & P value & Adjusted P \\
\hline Parapost XP & Light Post & 54 & 0.0010 & 0.0029 \\
\hline Light Post & Snowlight & 54 & 0.0481 & 0.1442 \\
\hline Snowlight & Parapost XP & 54 & $<0.0001$ & $<0.0001$ \\
\hline $10 \mathrm{~mm}$ & $5 \mathrm{~mm}$ & 54 & 0.0003 & 0.0003 \\
\hline
\end{tabular}

Figure 12 shows the average ultimate failure loads for each sample group. The corresponding group numerical averages, standard deviations, and significant differences after using a 1-way ANOVA and a Bonferroni adjustment are shown in Table 6. Although presented here, the ultimate failure load represents the point of catastrophic failure of a sample and it has less clinical relevance than the initial failure load. Table 7 shows that the post type $(\mathrm{p}<0.0001)$ had an effect on ultimate failure loads but the post length did not $(\mathrm{p}=0.5141)$. When analyzed further using 2-way ANOVA, as seen in Table 8, the Parapost XP groups were found to have significantly higher ultimate failure loads than the Light Post $(\mathrm{p}=0.0006)$ or Snowlight groups $(p<0.0001)$. The post length had no significant effect on the ultimate failure load for the test groups. 


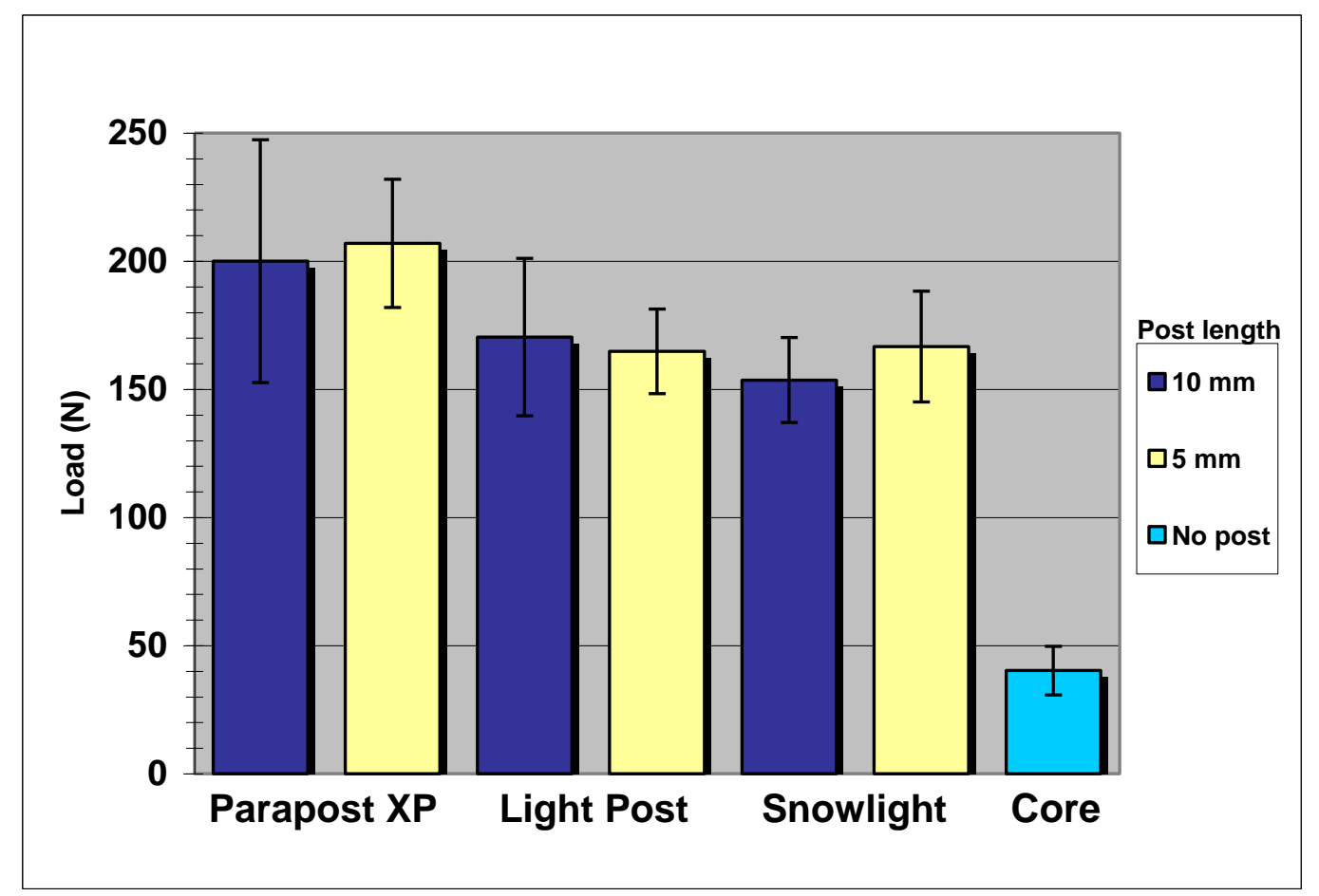

Figure 12: Average ultimate failure load based on post type and post length

Table 6: Group Differences of Least Squares Means Using 1-way ANOVA for Ultimate Failure Load After a Bonferroni Adjustment

\begin{tabular}{|c|c|c|c|c|}
\hline Post type & Length & $\begin{array}{c}\text { Mean failure load } \\
\quad \pm \text { SD }(\mathrm{N})\end{array}$ & $\begin{array}{l}\text { Mean max. failure } \\
\text { bending stress } \pm \mathrm{SD} \\
(\mathrm{MPa})\end{array}$ & $\begin{array}{c}\text { Sig. } \\
\text { Differences } \\
(\mathbf{p}<0.05)\end{array}$ \\
\hline Parapost XP & $5 \mathrm{~mm}$ & $206.94 \pm 25.00$ & $160.89 \pm 19.44$ & \\
\hline Parapost XP & $10 \mathrm{~mm}$ & $200.04 \pm 47.34$ & $155.52 \pm 36.81$ & \\
\hline Light Post & $10 \mathrm{~mm}$ & $170.34 \pm 30.67$ & $132.43 \pm 23.85$ & \\
\hline Snowlight & $5 \mathrm{~mm}$ & $166.67 \pm 21.65$ & $129.58 \pm 16.83$ & \\
\hline Light Post & $5 \mathrm{~mm}$ & $164.79 \pm 16.48$ & $128.12 \pm 12.81$ & \\
\hline Snowlight & $10 \mathrm{~mm}$ & $153.59 \pm 16.60$ & $119.41 \pm 12.90$ & \\
\hline Core (no post) & $\mathrm{N} / \mathrm{A}$ & $40.24 \pm 9.52$ & $31.28 \pm 7.40$ & \\
\hline
\end{tabular}

Note: Bars between groups indicate no significant difference Statistics were derived from t-test with $63 \mathrm{DF}$

Table 7: 2-way ANOVA for Ultimate Failure Load Based on Post Type and Post Length

\begin{tabular}{|l|c|c|c|c|}
\hline Effect & Num DF & Den DF & F Value & P value \\
\hline Post & 2 & 54 & 13.38 & $<0.0001$ \\
\hline Length & 1 & 54 & 0.43 & 0.5141 \\
\hline Post $x$ Length & 2 & 54 & 0.56 & 0.5743 \\
\hline
\end{tabular}


Table 8: Post Type and Length Differences of Least Squares Means Using 2-way ANOVA for Ultimate Failure Load After a Bonferroni Adjustment

\begin{tabular}{|c|c|c|c|c|}
\hline Post Type or Length & Post Type or Length & DF & P value & Adjusted P \\
\hline Parapost XP & Light Post & 54 & 0.0002 & 0.0006 \\
\hline Light Post & Snowlight & 54 & 0.4104 & 1.0000 \\
\hline Snowlight & Parapost XP & 54 & $<0.0001$ & $<0.0001$ \\
\hline $10 \mathrm{~mm}$ & $5 \mathrm{~mm}$ & 54 & 0.5141 & 0.5141 \\
\hline
\end{tabular}

The mode of ultimate failure for each test group is shown in Table 9. Identified in the table is a microscopic analysis of the tooth-core interface, the visual observation of ultimate failure, and a radiographic analysis of the samples. The microscopic analysis shows the number of tooth-core debonds in each group whereby the core was totally debonded from the tooth during loading. It should be noted that tooth-core debonding was not always sufficient to stop the applied load. Instead, samples were loaded to ultimate failure and either core fracture, corepost debonding, post pullout, root fracture, or a combination of these occurred. The radiographic analysis shows whether post bending occurred during loading and if any core-post debonding or post pullout occurred. The core-post debonding presented radiographically as a separation of the core from the post from the occlusal-most aspect of the post. Post pullout presented as open space at the post apex in the post space and either separation of the post from post cement or post cement pullout. The last column in the table indicates whether root fracture occurred.

Table 9: Mode of Ultimate Failure for Test Groups

\begin{tabular}{|c|c|c|c|c|c|}
\hline Post Type & Length & Microscopic & $\begin{array}{c}\text { Visual } \\
\text { Observation }\end{array}$ & Radiographic & $\begin{array}{c}\text { Root } \\
\text { Fractures }\end{array}$ \\
\hline Parapost XP & $10 \mathrm{~mm}$ & $\begin{array}{c}1 / 10 \text { total core } \\
\text { debonding }\end{array}$ & $9 / 10$ core fracture & $6 / 10$ post bending & $2 / 10$ \\
\hline Parapost XP & $5 \mathrm{~mm}$ & $\begin{array}{c}8 / 10 \text { total core } \\
\text { debonding }\end{array}$ & $6 / 10$ core fracture & $9 / 10$ post bending & $3 / 10$ \\
\hline Light Post & $10 \mathrm{~mm}$ & $\begin{array}{c}7 / 10 \text { total core } \\
\text { debonding }\end{array}$ & $8 / 10$ core fracture & $\begin{array}{c}4 / 10 \text { post bending } \\
4 / 10 \text { core/post debond }\end{array}$ & $0 / 10$ \\
\hline Light Post & $5 \mathrm{~mm}$ & $\begin{array}{c}10 / 10 \text { total core } \\
\text { debonding }\end{array}$ & $10 / 10$ core fracture & No post bending & $0 / 10$ \\
\hline Snowlight & $10 \mathrm{~mm}$ & $\begin{array}{c}8 / 10 \text { total core } \\
\text { debonding }\end{array}$ & $9 / 10$ core fracture & $\begin{array}{c}2 / 10 \text { post bending } \\
1 / 10 \text { core/post debond }\end{array}$ & $0 / 10$ \\
\hline Snowlight & $5 \mathrm{~mm}$ & $\begin{array}{c}10 / 10 \text { total core } \\
\text { debonding }\end{array}$ & $1 / 10$ core fracture & $\begin{array}{c}9 / 10 \text { post bending and } \\
\text { post pullout }\end{array}$ & $0 / 10$ \\
\hline $\begin{array}{c}\text { Control } \\
\text { (no post) }\end{array}$ & N/A & $\begin{array}{c}10 / 10 \text { total core } \\
\text { debonding }\end{array}$ & N/A & N/A & $0 / 10$ \\
\hline
\end{tabular}


Figures 13-18 present photomicrographs of selected samples that are representative of different modes of failure. Figure 13 shows ultimate failure of a Parapost XP sample with core fracture only. The samples from all groups typically experienced an initial failure in the form of tooth-core debonding. In Figure 14, a sample has undergone initial failure from tooth-core debonding and an ultimate failure from core fracture. Figures 15 and 16 show total core fracture from posts and Figure 16 also demonstrates fiber post bending. Figure 17 presents an initial failure from tooth-core debonding followed by root fracture. Root fracture was found in $25 \%$ of the Parapost XP groups as seen previously in Table 9. Figure 18 shows initial failure from tooth-core debonding and ultimate failure resulting from post bending and post pullout. The radiograph in Figure 19 shows a Snowlight $5 \mathrm{~mm}$ sample that exhibits both post pullout and core-post debonding as evidenced by voids at the occlusal and apical ends of the post.

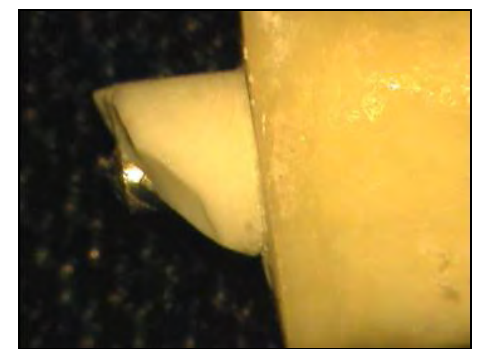

Figure 13: Parapost XP $10 \mathrm{~mm}$ showing vertical core fracture.

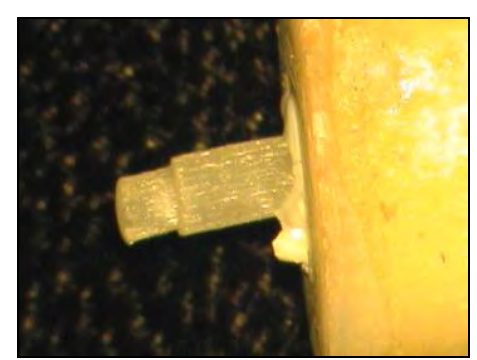

Figure 16: Light Post $10 \mathrm{~mm}$ showing tooth-core debond, core fracture, and post bending

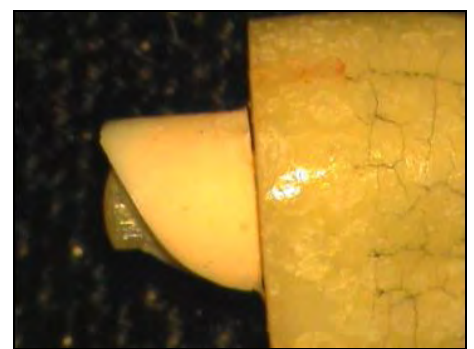

Figure 14: Light Post 10 mm showing tooth-core debond and core fracture.

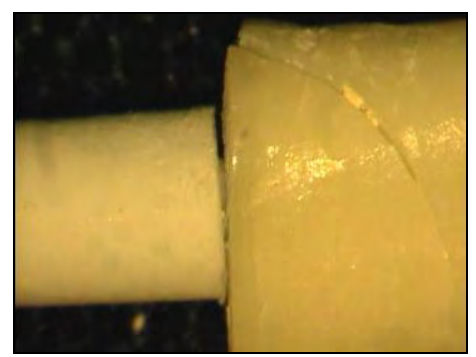

Figure 17: Parapost XP 5 mm showing tooth-core debond and subsequent root fracture.

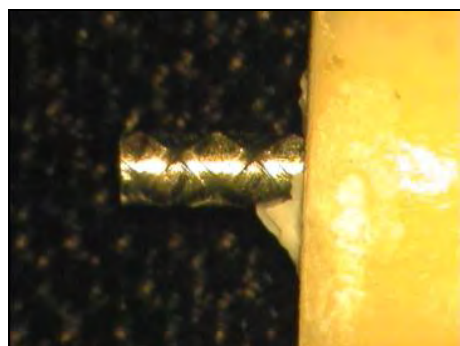

Figure 15: Parapost XP $10 \mathrm{~mm}$ showing total core fracture.

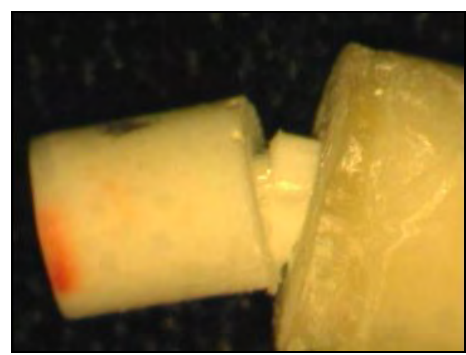

Figure 18: Snowlight $5 \mathrm{~mm}$ showing tooth-core debond, post bending, and post pullout.

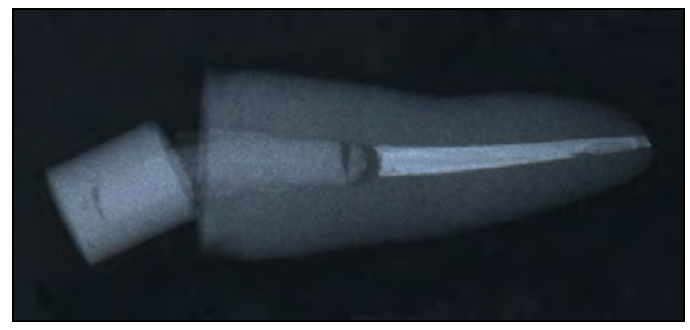

Figure 19: Snowlight $5 \mathrm{~mm}$ showing post pullout and core-post debonding. 


\section{DISCUSSION}

The design of fiber-reinforced posts has had a short history, dating back to 1990 when the first one was introduced by Duret, Reynaud \& Duret. ${ }^{(36)}$ Improvements in processing of fibers and quality control have since allowed for the development of pre-stressed glass and quartz fiber-reinforced posts, some having light-transmitting capability. The selection of the two light-transmitting posts for this study was intended to compare glass and quartz fiber-reinforced posts from two manufacturers with each other and to a standard stainless steel post. The light transmission capabilities of the posts was not measured in this study. Light-transmission of the posts permitted light- or dual-cured composite materials to be used for post cementation and core fabrication. In this study, an integrated technique was used to cement the posts and fabricate the core with the same composite resin material. This allowed for a uniform material to bond to the post and tooth structure and reduce the variability at the tooth-core interface. Posts were modified to be parallel, without threads or large retentive heads to reduce the variability in post design, especially with different post lengths tested. A non-eugenol sealer (AH Plus) was selected in order to be compatible with adhesive bonding of the composite resin. The dual-cure composite core material was selected because of its ability to bond to both the fiber-reinforced posts and tooth structure, and still be cured with the stainless steel post where light-activation within the root was not possible.

Placement of a crown ferrule has been shown to be an important factor in increasing the fracture resistance of teeth. However, this study attempted to simulate the clinical situation in which a crown ferrule cannot be placed and the load must be borne primarily from the post-andcore system. In addition, a perpendicular angle of loading was used in this study because it has been shown to be the most traumatic to a post-and-core system, and a likely manner in which many systems fail. Any load direction other than in the long axis of the post-and-core will incur a component of stress perpendicular to the long axis. The closer to $90^{\circ}$ this load is applied, the

greater the perpendicular stress component. Yang et. al. (2001) used a 2-D finite element model to show that horizontal loading and a short post induces high dentinal stresses within the root. ${ }^{33}$ It is theorized that failure of most post-and-core systems is due to the stress created perpendicular to the long axis. This may cause the coronal seal to break, debonding of a core, and with application of cyclic loads, the ultimate failure of the post-and-core system. Loss of 
retention due to debonding of the post-and-core system is the primary reason for metal post failure and may be responsible for a large portion of root fractures that occur.

Most manufacturers of fiber-reinforced post systems use the longitudinal elastic modulus as a measure of compatibility with tooth structure. However, using the elastic modulus may be less useful in the analysis of loading a post-and-core system perpendicular to the longitudinal axis. An estimation of the elastic modulus of a fiber-reinforced post can be made based on the fiber and matrix content. The maximum elastic modulus is in the longitudinal axis where the fibers are oriented lengthwise and in isostrain (strain of fibers and matrix is theoretically equivalent). This equation can be summarized as:

$$
\mathrm{E}_{\mathrm{l}}=\left(\mathrm{E}_{\mathrm{f}} \mathrm{V}_{\mathrm{f}}\right)+\left(\mathrm{E}_{\mathrm{m}} \mathrm{V}_{\mathrm{m}}\right)
$$

Where $E_{1}$ is the longitudinal elastic modulus, commonly reported as the elastic modulus by manufacturers. $V_{f}$ and $V_{m}$ are the volume of fiber and matrix, respectively, and $E_{f}$ and $E_{m}$ are the elastic modulus of fiber and matrix, respectively. The minimum elastic modulus, also known as the transverse modulus is where the fibers are oriented perpendicular to the load direction and in isostress (stress of fibers and matrix is theoretically equivalent). This equation can be summarized as:

$$
\left(1 / \mathrm{E}_{\mathrm{ct}}\right)=\left(\mathrm{V}_{\mathrm{f}} / \mathrm{E}_{\mathrm{f}}\right)+\left(\mathrm{V}_{\mathrm{m}} / \mathrm{E}_{\mathrm{m}}\right)
$$

Where $\mathrm{E}_{\mathrm{ct}}$ is the transverse modulus. In the transverse direction, the fiber and the post make limited contribution to the overall post-and-core transverse modulus. However, a direct measure of the bending stiffness of a fiber-reinforced post is the flexural modulus. Flexural modulus is the ratio of stress to strain within the elastic limit during bending of a material.

The flexural modulus of composite resin materials ranges from approximately 2.6$13 \mathrm{GPa},{ }^{(37)}$ with flowable or core composites on the lower end of the range. Dentin ranges from 18.5-21.8 GPa depending on the angle of loading and proximity of the dentin. ${ }^{(24)}$ In the experimental setup for this study, there were a variety of materials used, including the tooth, post, and composite resin core, each with a different flexural modulus. When components of a system have dissimilar moduli, shear stresses are created between materials that may exceed their bond strength. This will create areas of higher stress concentration, with the lowest modulus material developing the highest stresses.

During sample loading, it was determined that initial failure was occurring due to a drop in values within the loading curve. For some samples, this drop corresponded with a visible 
separation of the core from the tooth or catastrophic core fracture. For other samples, no visible separation was evident until later in loading. The loading curve initially follows a similar path as delamination of a composite material. During delamination, a drop or stasis occurs in the applied load. Due to the successive failure of individual components within the post-and-core samples, it was decided to load the samples to catastrophic failure. The catastrophic failure corresponded with the ultimate failure load as reported in Table 6. However, each loading curve was analyzed and the first decrease in load values was reported as the initial failure load. It is likely that in some samples, there was more than one site of failure formed subsequent to the initial failure. This would have been very technically difficult to ascertain. Due to the difficulty in determining the strain measurement from the extension values given by the Instron, the slope of each loading curve was not analyzed. Theoretically the loading curve could have been used to determine the point at which plastic deformation occurred within the post-and-core system and also the overall flexural modulus. A transducer measuring displacement may also have been connected to the core and tooth to determine the point of debonding and amount of separation occurring during loading similar to a study by Reagan et. al. ${ }^{(38)}$ In addition, this present study used static loading of samples. Cyclic loading may be more clinically relevant, but also has been found to produce large standard deviations with more technique sensitivity. ${ }^{(16,35,38)}$ These additional topics may warrant further investigation.

The statistical analysis for this study was straightforward. The composite core control group could not directly be compared to other groups using a 2-way ANOVA because no post was used. Therefore, a 1-way ANOVA with a Bonferroni adjustment was used to consider each group as a separate entity and allow for direct comparisons. The Bonferroni adjustment is a mathematical correction that can be used to reduce falsely significant results. By running more statistical tests on a given data set, there is an increasing likelihood of getting a significant result by chance alone. The adjustment multiplies the $\mathrm{p}$ value by the number of tests carried out to reduce the chance of having a Type I error. The downside of using the Bonferroni adjustment is that Type II errors (the probability of accepting a null hypothesis, when it is actually false) tend to increase. Therefore, there exists a chance that significant results may be lost. Thus, the results as presented in Tables 3-8 are a conservative estimate of significant differences.

The average maximum bending stress for each group was given to allow for future comparison to this study. These values also allow for discussion as to the stress gradients 
created in each post-and-core system during loading. A gradient of bending stress is created within the post-and-core system whereby the greatest stress is on the outside perimeter of the system, with a lower stress toward the inside. In the experimental setup, the theoretical bending stress at the center of the post-and-core was zero. Using this theory, a stiffer post (higher flexural modulus) would provide better stress transfer to the surrounding coronal structures because it will absorb a greater portion of the applied stress and remain intact. On the other hand, a more flexible post (lower flexural modulus) will tend to deform, transferring stress to the weaker surrounding coronal structures, such as the core or tooth. The disadvantage of using a stiffer post is that the root providing retention is fixed and must support the post during bending load application. Therefore, with the root bonded to the post, the root is also subjected to higher stresses with a high stiffness post. This was shown by a $25 \%$ root fracture rate when the higher flexural modulus Parapost XP posts were used. With a low stiffness post, the coronal post flexes, transferring the stresses to the core or tooth. Ideally there is a balance between support for the core and coronal tooth and the stress transfer to the root that limits the incidence of root fracture or post debonding.

The loading parameters were designed to be similar to a cantilever arrangement, whereby the post-and-core was subjected to a bending stress with the maximum being at the interface with the tooth. Once the bending stress surpasses the tensile bond strength between the core and the tooth, the core debonds from the tooth. However, the compressive bond strength of the core and tooth may not be reached until a greater load is applied. Therefore, the post-and-core may remain intact, with only slight separation of the core at the tensile load interface (buccal portion of the core). This is the phenomena that was observed with most samples where the buccal portion of the core debonded for initial failure. This was usually followed by lingual core debonding. Once fully debonded, core flexure while retained by the post led to several other modes of failure including core fracture, root fracture, post bending and pullout, and core-post debonding. Conversely, the results indicate that use of a post to support a core is warranted. The composite core controls had a lower mean initial and ultimate failure load than any sample groups. There was no evidence of post-cement debonding in any groups, and only a loss of post retention was evident in the Snowlight $5 \mathrm{~mm}$ group.

Also created during loading was a bending shear stress in the long axis of the post-andcore, with the post and core interfaces subjected to differences in tension and compression. This 
bending shear stress created during loading is related to the different flexural moduli of the post and core materials. Once the bending shear stress surpasses the shear bond strength between the post and core, the core debonds from the post. Due to the large area of interface between the post and core, it was expected that the bending shear stress would likely not exceed the shear bond strength between the two materials. However, in some samples, debonding occurred between the post and core as evidenced by x-ray analysis. This was likely due a bending shear stress created during loading that exceeded the weak bond between the post surface and core material.

As shown in the statistical analysis, the initial failure of samples showed significant differences with respect to the post type and post length. As mentioned previously, the higher flexural modulus of the Parapost XP likely provided more support for the core than either of the fiber-reinforced posts. The $10 \mathrm{~mm}$ posts also provided more support for the core, likely due to better resistance to bending and better stress transfer to the root. When viewed in terms of stress distribution, an increased flexural modulus post and longer post length appear to give more support to a core. A lower flexural modulus post or a shorter post shifts more of the load to the core and tooth. Once the core debonds, as was the case with most groups, post bending or core fracture are likely outcomes. There was no statistical difference between the Light Post and Snowlight groups in terms of initial failure. Although it is reported by the manufacturer that the quartz fiber-reinforced Light Post is a higher quality post than glass fiber-reinforced posts, no statistical difference could be found when the data was grouped. However, comparing individual group means without a Bonferroni adjustment, the Light Post $10 \mathrm{~mm}$ post group had a statistically higher average initial failure load than the Snowlight $10 \mathrm{~mm}$ or $5 \mathrm{~mm}$ post groups. The mechanical differences between the quartz and glass fiber-reinforced posts warrants further investigation.

The ultimate failure of samples showed significant differences with respect only to post type. However, the clinical significance of the ultimate failure values is in question. In a clinical situation, once initial failure of a post-and-core restoration has occurred, the restoration can be expected to fail thereafter from cyclic loading. Thus, the ultimate failure loads of groups was given for comparison purposes to previous studies that have only presented results based on catastrophic failure of samples. Nonetheless, it is important to note that the stresses following core debonding are placed primarily on the post. Thus, the post will either focus the stress on 
the root in the case of a stiffer post or will tend to bend and collapse any remaining core or pull the post out such as with a flexible post. Clinically translated, catastrophic failure with a metal post may present as root fracture or loss of post retention. Failure with a fiber-reinforced post may present as core or post debonding, leading to microleakage, and subsequent core or crown fracture.

When comparing the mode of failure (Table 9), it should be noted that the microscopic and radiographic examination occurred following ultimate failure. Thus, the results may not be indicative of a clinical situation. It is evident that only the Parapost XP $10 \mathrm{~mm}$ group did not typically exhibit full core debonding. While microscopically the Parapost XP $10 \mathrm{~mm}$ group showed some evidence of buccal core debonding, there was only one sample that showed full core debonding following ultimate failure. All other groups showed buccal core debonding for every sample. Two out of ten Parapost XP $10 \mathrm{~mm}$ and three out of ten Parapost $5 \mathrm{~mm}$ samples exhibited root fractures upon ultimate failure. No other samples from the fiber-reinforced groups exhibited root fractures. Root fracture of stainless steel samples may be due to the bending stress placed on the root following initial failure. The fiber-reinforced posts, with lower bending stiffness, did not transfer the same degree of bending stress to the root. Instead, the stress was transferred to the core and the post cement, as the post was plastically bent. This would account for the post pullout and post bending within the fiber-reinforced groups. Interestingly, the Light Post $5 \mathrm{~mm}$ group did not experience visible post bending or pullout. This may be due in part to a good bond to the post cement which did not allow for post pullout and subsequent post bending until core fracture had occurred. The Snowlight $5 \mathrm{~mm}$ group clearly had a loss of post retention at ultimate failure. Separation of the post-and-core from the tooth was obvious, as the load application acted as a lever on the core to pull the post from the root. From the results, it appears that the Snowlight $5 \mathrm{~mm}$ post length may not be adequate to provide sufficient retention to a composite core.

Preventing microleakage within post-and-core restorations is of primary importance. Once a coronal seal is broken, the root canal is susceptible to bacterial penetration and endodontic failure may occur. Therefore, separation of the core material from the coronal tooth structure is of clinical significance because it increases the chance for microleakage. In addition, the breakdown of the bond weakens the post-and-core system during cyclic loading and places more of the stress on the post and remaining root. 
Use of resin cement to increase the retention of posts is well documented. This study used two different length posts, but the retention was not evaluated. Instead, this study found that the post length has a statistically significant effect on the fracture resistance of post-and-core systems when a resin cement was used. Thus, a shorter post may provide adequate retention for a core, but may not provide as much resistance to bending and may place more stress on the root dentin when loaded. 


\section{CONCLUSIONS}

Based on the results of this study, the following conclusions can be drawn within the limitations of the experimental design:

1. The mean flexural modulus of the stainless steel Parapost XP (132.1 GPa) was higher than either the fiber-reinforced Light Post $(39.1 \mathrm{GPa})$ or Snowlight posts (38.2 GPa).

\section{INITIAL FAILURE OF SAMPLES}

2. The mean initial failure load for the Parapost XP $10 \mathrm{~mm}$ group was the highest (170.05 \pm $60.08 \mathrm{~N})$ and the Snowlight $5 \mathrm{~mm}$ group was the lowest $(62.85 \pm 18.47 \mathrm{~N})$ of those groups posts placed. There was a statistically significant difference between groups.

3. The stainless steel Parapost XP post-and-core groups had an initial failure load significantly higher than either the fiber-reinforced Light Post or Snowlight groups for the each of respective post lengths tested.

4. There was no significant difference in initial failure load between the quartz fiberreinforced Light Post and the glass fiber-reinforced Snowlight groups for each of the respective post lengths tested.

5. The $10 \mathrm{~mm}$ length post-and-core groups had an initial failure load significantly higher than the $5 \mathrm{~mm}$ length post-and-core groups.

6. The mode of initial failure for all groups was core debonding from the tooth, except for the Parapost XP $10 \mathrm{~mm}$ group, which also had core fractures.

\section{ULTIMATE FAILURE OF SAMPLES}

7. The mean ultimate failure load for the Parapost XP $5 \mathrm{~mm}$ group was the highest (206.94 $\pm 25.00 \mathrm{~N})$ and the Snowlight $10 \mathrm{~mm}$ group was the lowest $(153.59 \pm 16.60 \mathrm{~N})$ of those groups with posts placed. There was a statistically significant difference between groups. 
8. The stainless steel Parapost XP post-and-core groups had an ultimate failure load significantly higher than either the fiber-reinforced Light Post or Snowlight groups for the each of respective post lengths tested.

9. There was no significant difference in ultimate failure load between the quartz fiberreinforced Light Post and the glass fiber-reinforced Snowlight groups for each of the respective post lengths tested.

10. The $10 \mathrm{~mm}$ length post-and-core groups were not statistically different from the $5 \mathrm{~mm}$ length post-and-core groups for ultimate failure load.

11. The mode of ultimate failure created $25 \%$ root fractures in stainless steel Parapost XP groups, but did not create any root fractures in the fiber-reinforced Light Post or Snowlight groups. 


\section{REFERENCES}

1. Fredriksson M, Astback J, Pamenius M, Arvidson K. A retrospective study of 236 patients with teeth restored by carbon fiber-reinforced epoxy resin posts. J Prosthet Dent 1998; 80:151-7.

2. Ferrari M, Vichi A, Garcia-Godoy F. Clinical evaluation of fiber-reinforced epoxy resin posts and cast post and cores. Am J Dent 2000; 13:15B-18B.

3. Ferrari M, Vichi A, Mannocci F, Mason P. Retrospective study of the clinical performance of fiber posts. Am J Dent 2000; 13:9B-13B.

4. Mannocci F, Ferrari M, Watson T. Microleakage of endodontically treated teeth restored with fiber posts and composite cores after cyclic loading: A confocal microscopic study. J Prosthet Dent 2001;85:284-91.

5. Duncan J, Pameijer C. Retention of parallel-sided titanium posts cemented with six luting agents: an in vitro study. J Prosthet Dent 1998; 80:423-8.

6. Cohen B, Pagnillo M, Newman I, Musikant B, Deutsch A. Retention of three endodontic posts cemented with five dental cements. J Prosthet Dent 1998; 79:520-5.

7. Love R, Purton D. Retention of posts with resin, glass ionomer and hybrid cements. J Dent 1998; 599-602.

8. Drummond J. In vitro evaluation of endodontic posts. Am J Dent 2000; 13:5B-8B.

9. Gallo J, Miller T, Xu X, Burgess J. In vitro evaluation of the retention of composite fiber and stainless steel posts. J Prosthodont 2002; 11:25-9.

10. El-mowafy O, Milenkovic M. Retention of paraposts cemented with dentin-bonded resin cements. Oper Dent 1994; 19:176-182.

11. Ferrari M, Mannocci F. A 'one-bottle' adhesive system for bonding a fibre post into a root canal: an SEM evaluation of the post-resin interface. International Endondontic Journal 2000; 33:397-400.

12. Mannocci F, Innocenti M, Ferrari M, Watson T. Confocal and scanning electron microscopic study of teeth restored with fiber posts, metal posts, and composite resins. J Endodont 1999; 25:789-794.

13. Nissan J, Dmitry Y, Assif D. The use of reinforced composite resin cement as compensation for reduced post length. J Prosthet Dent 2001; 86:304-8.

14. Cohen B, Condos S, Musikant B, Deutsch A. Retention properties of a split-shaft threaded post: cut at different apical lengths. J Prosthet Dent 1992; 68:894-8. 
15. Love R, Purton D. The effect of serrations on carbon fibre posts - retention within the root canal, core retention, and post rigidity. Int J Prosthodont 1996; 9:484-8.

16. Isidor F, Brondum K, Ravnholt G. The influence of post length and crown ferrule length on the resistance to cyclic loading of bovine teeth with prefabricated titanium posts. Int $\mathrm{J}$ Prosthodont 1999; 12:78-82.

17. Saupe W, Gluskin A, Radke R. A comparative study of fracture resistance between morphologic dowel and cores and a resin-reinforced dowel system in the intraradicular restoration of structurally compromised roots. Quintessence Int 1996; 27:483-491.

18. Mendoza D, Ealde W, Kahl E, Ho R. Root reinforcement with a resin-bonded preformed post. J Prosthet Dent 1997; 78:10-15.

19. Jiménez, M. Fracture resistance and mode of failure of endodontically treated teeth restored with fiber reinforced posts. 2001. Masters of Science Thesis in Restorative Dentistry, The University of Michigan School of Dentistry, Ann Arbor, MI.

20. Torbjorner A, Karlsson S, Syverud M, Hensten-Pettersen A. Carbon fiber reinforced root canal posts - mechanical and cytotoxic properties. Eur J Oral Sci 1996; 104:605611.

21. Mannocci F, Sherriff M, Watson T. Three-point bending test of fiber posts. J Endodont $2001 ; 27: 758-761$.

22. Asmussen E, Peutzfeldt A, Heitmann T. Stiffness, elastic limit, and strength of newer types of endodontic posts. J Dent 1999; 27:275-8.

23. Purton D, Love R. Rigidity and retention of carbon fibre versus stainless steel root canal posts. Int Endodont J 1996; 29:262-5.

24. Mayazaki M, Inage $\mathrm{H}$, Onose $\mathrm{H}$. Use of an ultrasonic device for the determination of elastic modulus of dentin. J Oral Sci 2002; 44:19-26.

25. Martinez-Insua A, Da Silva L, Rilo B, Santana U. Comparison of the fracture resistances of pulpless teeth restored with a cast post and core or carbon-fiber post with a composite core. J Prosthet Dent 1998; 80:527-532.

26. Sidoli G, King P, Setchell D. An in vitro evaluation of a carbon fiber-based post and core system. J Prosthet Dent 1997; 78:5-9.

27. Sirimai S, Riis D, Morgano S. An in vitro study of the fracture resistance and the incidence of vertical root fracture of pulpless teeth restored with six post-and-core systems. J Prosthet Dent 1999; 81:262-9. 
28. Akkayan B. Gulmez T. Resistance to fracture of endodontically treated teeth restored with different post systems. J Prosthet Dent 2002; 87:431-7.

29. Cormier C, Burns D, Moon P. In vitro comparison of the fracture resistance and failure mode of fiber, ceramic, and conventional post systems at various stages of restoration. $\mathrm{J}$ Prosthodont 2001; 10:26-35.

30. CRA Journal. Which post has highest strength? Comparison of 7 Posts. www.cranews.com/newsletter/highlights/1998/98-11/posts/index.htm. November 1998.

31. Rosentritt M, Furer C, Behr M, Lang R, Handel G. Comparison of in vitro fracture strength of metallic and tooth-coloured posts and cores. J Oral Rehabil 2000; 27:595601.

32. Pegoretti A, Fambri, L, Zappini G, Bianchetti M. Fine element analysis of a glass fibre reinforced composite endodontic post. Biomaterials 2002; 23:2667-2682.

33. Yang H, Lang L, Molina A, Felton, D. The effects of dowel design and load direction on dowel-and-core restorations. J Prosthet Dent 2001; 85:558-67.

34. Huysmans M, Peters M, Plasschaert A, Vander Varst P. Failure characteristics of endodontically treated premolars restored with a post and direct restorative material. Int Endodont J 1992; 25:121-9.

35. Hsu Y, Nicholls J, Phillips K, Libman W. Effect of core bonding on fatigue failure of compromised teeth. Int J Prosthodont 2002; 15:175-8.

36. Duret B, Reynaud M, Duret F. Un nouveau concept de reconstruction coronoradiculaire: Le composiposte. Chirurg Dent France 1990; 540:131-141.

37. Craig R, Powers J. Editors. Restorative Dental Materials. $11^{\text {th }}$ Edition. St. Louis, 2002, Mosby.

38. Reagan S, Fruits T, Van Brunt C, Ward C. Effects of cyclic loading on selected postand-core systems. Quintessence Int 1999; 30:61-7. 


\section{APPENDICES}

Parapost XP 10 mm group

\begin{tabular}{|c|c|c|}
\hline Sample & $\begin{array}{c}\text { Initial } \\
\text { Failure } \\
\text { Load (N) }\end{array}$ & $\begin{array}{c}\text { Ultimate } \\
\text { Failure } \\
\text { Load (N) }\end{array}$ \\
\hline 1 & 199.31 & 199.31 \\
\hline 2 & 246.34 & 246.34 \\
\hline 3 & 138.83 & 157.08 \\
\hline 4 & 152.94 & 152.94 \\
\hline 5 & 260.52 & 260.52 \\
\hline 6 & 144.57 & 144.57 \\
\hline 7 & 118.45 & 216.13 \\
\hline 8 & 222.21 & 222.21 \\
\hline 9 & 71.35 & 143.71 \\
\hline 10 & 145.99 & 257.55 \\
\hline Average & $\mathbf{1 7 0 . 0 5}$ & $\mathbf{2 0 0 . 0 4}$ \\
\hline SD & $\mathbf{6 0 . 0 8}$ & $\mathbf{4 7 . 3 4}$ \\
\hline
\end{tabular}

Light Post $10 \mathrm{~mm}$ group

\begin{tabular}{|c|c|c|}
\hline Sample & $\begin{array}{c}\text { Initial } \\
\text { Failure } \\
\text { Load (N) }\end{array}$ & $\begin{array}{c}\text { Ultimate } \\
\text { Failure } \\
\text { Load (N) }\end{array}$ \\
\hline 1 & 159.39 & 159.39 \\
\hline 2 & 159.28 & 159.28 \\
\hline 3 & 84.78 & 138.42 \\
\hline 4 & 98.29 & 237.25 \\
\hline 5 & 73.90 & 154.71 \\
\hline 6 & 168.96 & 168.96 \\
\hline 7 & 122.63 & 158.97 \\
\hline 8 & 202.74 & 202.74 \\
\hline 9 & 97.78 & 185.91 \\
\hline 10 & 65.15 & 137.78 \\
\hline Average & $\mathbf{1 2 3 . 2 9}$ & $\mathbf{1 7 0 . 3 4}$ \\
\hline SD & $\mathbf{4 6 . 6 4}$ & $\mathbf{3 0 . 6 7}$ \\
\hline
\end{tabular}

$\underline{\text { Snowlight } 10 \mathrm{~mm} \text { group }}$

\begin{tabular}{|c|c|c|}
\hline Sample & $\begin{array}{c}\text { Initial } \\
\text { Failure } \\
\text { Load (N) }\end{array}$ & $\begin{array}{c}\text { Ultimate } \\
\text { Failure } \\
\text { Load (N) }\end{array}$ \\
\hline 1 & 104.46 & 150.49 \\
\hline 2 & 60.25 & 132.48 \\
\hline 3 & 58.27 & 184.40 \\
\hline 4 & 125.24 & 155.44 \\
\hline 5 & 49.13 & 144.84 \\
\hline 6 & 33.43 & 131.72 \\
\hline 7 & 77.16 & 165.72 \\
\hline 8 & 38.28 & 164.72 \\
\hline 9 & 48.19 & 141.98 \\
\hline 10 & 109.90 & 164.08 \\
\hline Average & $\mathbf{7 0 . 4 3}$ & $\mathbf{1 5 3 . 5 9}$ \\
\hline SD & $\mathbf{3 2 . 2 6}$ & $\mathbf{1 6 . 6 0}$ \\
\hline
\end{tabular}

Parapost XP 5 mm group

\begin{tabular}{|c|c|c|}
\hline Sample & $\begin{array}{c}\text { Initial } \\
\text { Failure } \\
\text { Load (N) }\end{array}$ & $\begin{array}{c}\text { Ultimate } \\
\text { Failure } \\
\text { Load (N) }\end{array}$ \\
\hline 1 & 162.55 & 204.11 \\
\hline 2 & 163.85 & 163.85 \\
\hline 3 & 49.05 & 209.10 \\
\hline 4 & 196.97 & 246.64 \\
\hline 5 & 110.54 & 229.60 \\
\hline 6 & 120.84 & 181.39 \\
\hline 7 & 98.02 & 201.76 \\
\hline 8 & 81.61 & 196.64 \\
\hline 9 & 69.59 & 200.40 \\
\hline 10 & 57.76 & 235.89 \\
\hline Average & $\mathbf{1 1 1 . 0 8}$ & $\mathbf{2 0 6 . 9 4}$ \\
\hline SD & $\mathbf{4 9 . 8 4}$ & $\mathbf{2 5 . 0 0}$ \\
\hline
\end{tabular}

$\underline{\text { Light Post } 5 \text { mm group }}$

\begin{tabular}{|c|c|c|}
\hline Sample & $\begin{array}{c}\text { Initial } \\
\text { Failure } \\
\text { Load (N) }\end{array}$ & $\begin{array}{c}\text { Ultimate } \\
\text { Failure } \\
\text { Load (N) }\end{array}$ \\
\hline 1 & 45.52 & 166.94 \\
\hline 2 & 37.47 & 145.57 \\
\hline 3 & 69.27 & 157.88 \\
\hline 4 & 57.72 & 141.46 \\
\hline 5 & 38.74 & 177.59 \\
\hline 6 & 47.48 & 173.59 \\
\hline 7 & 55.64 & 171.68 \\
\hline 8 & 150.17 & 189.98 \\
\hline 9 & 51.48 & 177.91 \\
\hline 10 & 89.01 & 145.26 \\
\hline Average & $\mathbf{6 4 . 2 5}$ & $\mathbf{1 6 4 . 7 9}$ \\
\hline SD & $\mathbf{3 3 . 8 3}$ & $\mathbf{1 6 . 4 8}$ \\
\hline
\end{tabular}

Snowlight $5 \mathrm{~mm}$ group

\begin{tabular}{|c|c|c|}
\hline Sample & $\begin{array}{c}\text { Initial } \\
\text { Failure } \\
\text { Load (N) }\end{array}$ & $\begin{array}{c}\text { Ultimate } \\
\text { Failure } \\
\text { Load (N) }\end{array}$ \\
\hline 1 & 82.41 & 161.00 \\
\hline 2 & 50.53 & 144.31 \\
\hline 3 & 59.72 & 195.45 \\
\hline 4 & 93.34 & 137.59 \\
\hline 5 & 70.11 & 148.31 \\
\hline 6 & 41.85 & 188.14 \\
\hline 7 & 78.88 & 144.83 \\
\hline 8 & 66.67 & 182.57 \\
\hline 9 & 43.07 & 182.85 \\
\hline 10 & 41.90 & 181.60 \\
\hline Average & $\mathbf{6 2 . 8 5}$ & $\mathbf{1 6 6 . 6 7}$ \\
\hline SD & $\mathbf{1 8 . 4 7}$ & $\mathbf{2 1 . 6 5}$ \\
\hline
\end{tabular}

Core control (no post) group

\begin{tabular}{|c|c|}
\hline Sample & $\begin{array}{c}\text { Ultimate } \\
\text { Failure } \\
\text { Load (N) }\end{array}$ \\
\hline 1 & 36.34 \\
\hline 2 & 32.61 \\
\hline 3 & 37.39 \\
\hline 4 & 48.45 \\
\hline 5 & 57.61 \\
\hline 6 & 43.12 \\
\hline 7 & 44.02 \\
\hline 8 & 23.75 \\
\hline 9 & 45.44 \\
\hline 10 & 33.62 \\
\hline Average & $\mathbf{4 0 . 2 4}$ \\
\hline SD & $\mathbf{9 . 5 2}$ \\
\hline
\end{tabular}

